\title{
Critical care management of traumatic brain injury
}

Handbook of Clinical Neurology 2017

Final submitted version corrected for changes during editorial processing

(with the permission of the publishers)

\author{
DK Menon ${ }^{1, *}$ and A Ercole ${ }^{1}$
}

\author{
${ }^{1}$ Division of Anaesthesia, University of Cambridge and Neurosciences/Trauma Critical Care \\ Unit, Addenbrooke's Hospital,Cambridge, UK \\ ${ }^{*}$ Corresponding author. Email dkm13@cam.ac.uk
}

\begin{abstract}
Traumatic brain injury (TBI) is a growing global problem, which is responsible for a substantial burden of disability and death, and which generates substantial healthcare costs. High-quality intensive care can save lives and improve the quality of outcome. TBI is extremely heterogeneous in terms of clinical presentation, pathophysiology, and outcome. Current approaches to the critical care management of TBI are not underpinned by high-quality evidence, and many of the current therapies in use have not shown benefit in randomized control trials. However, observational studies have informed the development of authoritative international guidelines, and the use of multimodality monitoring may facilitate rational approaches to optimizing acute physiology, allowing clinicians to optimize the balance between benefit and risk from these interventions in individual patients. Such approaches, along with the emerging impact of advanced neuroimaging, genomics, and protein biomarkers, could lead to the development of precision medicine approaches to the intensive care management of TBI.
\end{abstract}

\section{Introduction}

Traumatic brain injury (TBI) is an important cause for admission to intensive care units (ICUs) in general, and to neurocritical care units in particular. National population-based figures for ICU caseload (as opposed to more specific stratification into mild, moderate, or severe TBI) are difficult to find, but the UK Intensive Care National Audit and Research Centre (ICNARC, 2015) reported that in 2014-2015, approximately $2 \%$ of all ICU admissions and about $10 \%$ of admissions to neurocritical care units were due to TBI. These patients are at high risk of death or poor neurological outcome. Mortality in a 3200-patient cohort study from this population base (Harrison et al., 2013) was $18 \%$ at ICU discharge, rising to $26 \%$ at 6 months. Independent survival by 6 months was only achieved in $39 \%$ of patients. Other global data suggest similar outcome figures in hospitalized patients, though data from large, unselected case series based on ICU populations (rather than specific data on moderate or severe TBI) are not widely available. However, a comparative analysis of UK and US data suggested that TBI patients admitted to critical care services in the USA may have a less severe overall distribution of severity, with about half not being mechanically ventilated at admission from the emergency room (Wunsch et al., 2011). This is unsurprising, given that the USA has about twice the number of ICU beds in a population-based analysis, and it would be reasonable to infer that the absolute caseload from TBI may be higher in US ICUs, but TBI severity may be lower, and crude outcomes better. However, the wider TBI data suggest a similar large burden of case mix adjusted mortality and morbidity.

This burden of mortality and residual disability demands a comprehensive therapeutic response. However, despite substantial efforts and investment by the pharmaceutical industry, we still do not have a specific neuroprotective therapy that is effective in clinical TBI, and we may need to look elsewhere to improve outcomes (Menon and Maas, 2015). Little can be done about the extent of primary injury to the brain when patients present to ICUs following head trauma, but the detrimental contribution to outcome from secondary neuronal injury can be substantial. Much of such secondary injury, and (at least currently) all of the avoidable secondary injury, is triggered by physiological insults to the injured brain, which can be substantially mitigated by good neurocritical care. While accumulating evidence from case series and historic comparisons suggest that the overall process of protocol-driven neurocritical care may make a difference in this setting (English et al., 2013), this benefit has been more difficult to demonstrate in formal randomized controlled trials of specific interventions. Given this context, this chapter not only summarizes the clinical evidence available, but also seeks to 


\begin{tabular}{ll}
\hline Focal pathology & Nonfocal pathology \\
\hline \hline Extradural haematoma (EDH) & Global ischaemia \\
Subdural haematoma (SDH) & Traumatic axonal injury \\
Traumatic intracerebral haematoma (TICH) & Diffuse brain swelling \\
Contusions & Posttraumatic hydrocephalus \\
\hline
\end{tabular}

Table 1: Focal and nonfocal pathology in traumatic brain injury.

provide a basis for rational clinical management based on knowledge of pathophysiology where the paucity of trial evidence makes definitive formal recommendations impossible.

\section{$2 \quad$ Epidemiology}

There have been several attempts to provide a robust and objective definition of TBI. Most recently, an interagency working party defined TBI as "an alteration in brain function or other evidence of brain pathology caused by an external force" (Menon et al., 2010). This statement highlighted potential diagnostic confounders, and sought to rely on a combination of injury narrative, symptoms, neuroimaging, and wider context to establish a diagnosis. Despite these efforts, good data on TBI epidemiology are hard to find. Pooling of available age-adjusted incidence rates for the general population revealed that the reported incidence of TBI varies considerably, ranging from 59.6 to 811.0 per 100,000 (Roozenbeek et al., 2013). Figures for population-based ICU admissions with TBI are even scarcer, due to difficulties in defining the population denominator in most studies.

Notwithstanding difficulties with epidemiological definition and categorization, it is clear that TBI is an important cause of mortality and morbidity across the world, and that its global impact is rising. Despite the predicted incidence of dementia over the coming decades, it is salutary to note that TBI is estimated to remain, by far, the most important cause of neurodisability up to 2030 (WHO, 2006). However, the epidemiological pattern of TBI is changing globally (Roozenbeek et al., 2013). In high-income countries such as the USA, there is growing concern about the long-term impact of mild TBI and concussion, but such patients are unlikely to present to critical care units. However, increasing road usage in low- and middle-income countries, unaccompanied by appropriate traffic education and road safety measures, has increased the incidence of moderate and severe TBI. High-income countries have seen a marked increase in TBI, predominantly due to falls, in older patients. The availability of better prehospital facilities means that many patients with severe extracranial trauma are now surviving, and though associated intracranial injury may not be dominant in these subjects, the physiological compromise of severe critical illness means that many of these patients may have late disability associated with lesser severities of TBI. Finally, there is increasing concern that patients who sustain even a single moderate or severe TBI are at risk of increased mortality for decades after the ictus (McMillan et al., 2014; Greenwald et al., 2015; Puljula et al., 2016). Furthermore, survivors may carry a substantial burden of chronic (and possibly progressive) disability (Masel, 2015), and a minority may experience progressive cognitive and/or neurological deterioration (McMillan et al., 2012), as well as an increased risk of late neurodegenerative disease (Shively et al., 2012; Smith et al., 2013). These issues are relevant to our current and future care of TBI in critical care settings.

\section{Clinical neuropathology and pathophysiology}

Acute neuropathology following TBI (Blumbergs et al., 2008) determines early treatment, and can characterize acute pathophysiology. Acute neuropathology has conventionally been categorized as either focal or diffuse (Table 1). At later stages, the pathological changes seen in survivors can explain disability and deficits (Adams et al., 1999, 2011; Maxwell et al., 2004). Finally, the associations of TBI with late neurodegeneration, including Alzheimer's disease and chronic traumatic encephalopathy, have been primarily recognized by neuropathological studies (Smith et al., 2013; Daneshvar et al., 2015).

\subsection{Focal pathology}

Epidural haematomas (EDHs) account for $10 \%$ of cases of intracranial haemorrhage in TBI, and are associated in the majority of cases with skull fractures (classically of the middle meningeal artery, associated with fractures of the squamous temporal plate). An EDH may be associated with minimal or no underlying brain injury, and since bleeding into the extradural space needs to strip the dura from the inner table of the skull, haematoma accumulation may be slow, and patients may initially appear well and later deteriorate - often termed a "lucid interval" in patients who "talk and die" (Reilly et al., 1975). While this picture has been classically associated with EDH, more recent reports suggest other pathological substrates, including bifrontal contusions, 
coagulopathy, or anticoagulant medication (Goldschlager et al., 2007; Peterson and Chesnut, 2011; Kim et al., 2013). Classically, subdural haematomas (SDHs) commonly arise from rupture of bridging veins, and are often associated with underlying brain injury. However, bleeding into the subdural space may develop with minimal brain trauma in elderly patients on anticoagulants. Traumatic intracerebral haemorrhage (TICH) is commonly associated with superficial contusions, ormay be deep-seated (e.g., in the basal ganglia) as a consequence of shearing forces. Superficial contusions commonly occur as a consequence of coup or contrecoup impacts, most commonly in the frontal and temporal lobes, where the moving brain impacts the irregular inner surface of the skull. Where such haemorrhagic contusions are in continuity with an overlying SDH, the term "burst lobe" is sometimes applied. Intracranial haemorrhages represent the most common indication for surgical intervention following TBI, and can produce mass effect either because of their volume, or (particularly with SDH or TICH), due to the perilesional edema that commonly develops. Such mass effect may be delayed, particularly with bifrontal contusions, or can develop suddenly following a delay with temporal lesions, as an expanding contusion or haemorrhage that was originally confined to the temporal fossa enlarges and produces a more generalized effect. Contusion expansion is associated with microvascular failure, and may have a stereotyped molecular narrative, in which the sulfonylurea receptor (Sur 1) may play an important part (Simard et al., 2012).

\section{$3.2 \quad$ Nonfocal (diffuse) pathology}

The phrase "diffuse pathology" is a misnomer, since all three classic forms of this pathology are more likely to be multifocal, rather than diffuse. Ischaemia is common in the first 24 hours after TBI, and focal infarcts are frequent $(90 \%)$ in fatal TBI, either in watershed perfusion zones, or less commonly as a consequence of blunt vascular injury (Graham et al., 1978, 1989). Less commonly, true global ischaemia may occur, often triggered by a long period of refractory intracranial hypertension or systemic hypotension. Traumatic axonal injury (TAI) (Hill et al., 2016) arises as a consequence of acceleration-deceleration rotational forces and affects white-matter bundles in the brain, classically involving the dorsolateral brainstem, corpus callosum, and the corona radiata, most often in the frontal and temporal regions. When extensive, it is commonly referred to as diffuse axonal injury (DAI). Axons can also be injured at the interface of gray and white matter, at the point at which they enter the cortical mantle. While some axons can be physically sheared at the time of initial impact (primary axotomy), TAI can be more subtle and result in beading or undulation of axons with cytoskeletal damage, and matures due to metabolic or functional derangements in energy production or axonal transport, with late axonal breakdown (secondary axotomy). The maturation of TAI processes may take hours to days, and the activation of neuroinflammation that accompanies TBI may result in ongoing whitematter loss over months to years.

The clinical impact of TAI is variable, and mild TAI may simply result in a period of loss of consciousness. However, extensive DAI probably provides the substrate for the worst outcomes seen in TBI. TAI is commonly accompanied by injury to the small vessels that accompany white-matter bundles. While the resulting microhaemorrhages were simply viewed as a convenient biomarker of TAI, there has been recent interest in traumatic vascular injury as an important pathology in its own right (Kenney et al., 2016), although the relationship of radiologically or pathologically detectable TBI to abnormal vascular function in TBI is as yet unclear.

\subsection{Genetic modulation of disease course and outcome in TBI}

Only $35 \%$ of the variance in outcome can be explained by available prognostic models (see later section). It is likely that at least part of the residual variance in disease course and outcome could be explained by genetic variability in the host response, both in the acute and the postacute phases.

Mitochondrial DNA haplotype K, which is overrepresented amongst centenarians and underrepresented in neurodegenerative disease, is associated with better global outcomes (Bulstrode et al., 2014), and carriers of haplotypes K, I, and J are less disabled following TBI (Conley et al., 2014). Intronic variations in the antiapoptotic proto-oncogene BCL2 are associated with poor outcome in severe TBI (Hoh et al., 2010). Polymorphisms in genes coding for several cytokines have been shown to modulate TBI outcome, including tumor necrosis factor- $\alpha$ (TNF- $\alpha$ ) (Waters et al., 2013), interleukin-1 $\beta$ (IL-1 $\beta$ ) (Uzan et al., 2005), and IL-1Ra (Hadjigeorgiou et al., 2005). Heterozygotes at a single-nucleotide polymorphism in IL-1 $\beta$ also showed substantially higher risk of posttraumatic seizure development (over 36-month follow-up) in one cohort (Diamond et al., 2014). In the postacute phase, outcome has been shown to be associated with polymorphisms in genes coding for brain-derived neurotrophic factor, though some results are conflicting (Krueger et al., 2011; McAllister et al., 2012; Barbey et al., 2014). Polymorphisms in a range of neurotransmitter-related genes also modulate outcome. These include the GRIN2A gene, which codes for an NMDAR subunit (Raymont et al., 2008), genes responsible for dopamine signaling (e.g., Val158Met polymorphism in the gene coding for catechol-O-methyltransferase, or the ANKK1 gene modulating expression of the DRD2 dopamine receptor) (Lipsky et al., 2005; McAllister et al., 2008; Willmott et al., 2013; Yue et al., 2015;Winkler et al., 2016), and serotonin transport protein, 5-HTTLPR (Failla et al., 2013). The most extensively studied gene in the field of TBI is the cholesterol transport protein, apolipoprotein E, which has three well-characterized alleles $(\epsilon 2,3$, and 4$)$. Possession of the $\epsilon 4$ allele is known 
to increase the risk of late-onset Alzheimer's disease, and has been shown in several studies to worsen outcome or the trajectory of recovery from TBI (Teasdale et al., 1997, 2005; Ponsford et al., 2011; Lawrence et al., 2015). Possession of this allele also increases the risk of late dementia following TBI. This risk is modulated by age and TBI severity (see Shively et al., 2012, for review), but the combination of an $\epsilon 4$ allele and a history of severe TBI may increase late dementia risk 10-fold. While all of these effects have been attributed to late modulation of cognitive outcome, genetic variations may also modulate pathophysiology in the acute phase. For example, neurotransmitter dynamics are known to play a part in secondary neuronal injury, and $\epsilon 4$ inhibits neurite outgrowth and increases release of proinflammatory mediators (IL-6, nitric oxide) from stimulated microglia (Vitek et al., 2009).

\subsection{Molecular mechanisms of injury}

The molecular mechanisms of injury in TBI resemble those seen in other acute insults such as ischaemia, and have been reviewed elsewhere (Kochanek et al., 2015; Krishnamurthy and Laskowitz, 2015). Briefly, secondary injury mechanisms include excitotoxicity and calcium influx, oxidative injury (through lipid peroxidation, protein nitrosylation, and DNA damage), cellular and humoral inflammatory mediators, and energy failure, which result in secondary neuronal loss through a range of cell death modes (necrosis, apoptosis, necroptosis, paraptosis, parthanosis, autophagy, and phagoptosis of injured but viable cells by activated microglia).

\subsection{Brain swelling, dysautoregulation and energy failure}

Brain swelling in TBI is classically attributed to cytotoxic edema, vasogenic edema, or vascular congestion, which have time-varying profiles after TBI (Fig. 1). Original support for the role of vascular congestion in causing brain swelling (Kelly et al., 1996) was challenged by the increasing use of diffusion-weighted magnetic resonance imaging (MRI) in this context over the last 15 years, which led to an increased focus on cytotoxic edema (Kawamata et al., 2000; Kucinski et al., 2002; Marmarou et al., 2006; Pasco et al., 2006), but on its own, this process only results in a translocation of water from the interstitial space to the cellular compartment, and no increase in overall brain volume (Donkin and Vink, 2010). More recent publications have renewed interest in microvascular injury (Logsdon et al., 2015), vasogenic edema (resulting from altered blood-brain barrier (BBB) permeability (Price et al., 2015)), and the cerebral venous compartment (Chen et al., 2015) as important causes of brain swelling. Cytotoxic edema may arise from either reduced energy supply or increased energy demand. Systemic hypoxia and hypotension are important causes of inadequate oxygen and substrate delivery, and powerful modulators of outcome (Chesnut et al., 1993; Jones et al., 1994; Manley et al., 2001). However, even if systemic physiology is well maintained, classic ischaemia can be seen, commonly within the first 24 hours after TBI (Bouma et al., 1991, 1992; Coles et al., 2004), and often in relation to contusions and SDHs. Additional contributors to impaired energy generation (Fig. 2) include tissue hypoxia arising from impaired oxygen diffusion, microvascular ischaemia (Menon et al., 2004), or mitochondrial dysfunction causing metabolic crisis (Verweij et al., 2000; Vespa et al., 2005). Mitochondrial dysfunction may be due to mechanical disruption of mitochondria, or due to competitive inhibition in the respiratory chain by elevated levels of nitric oxide (Brown, 2000). These different models of energy failure have similar consequences in terms of metabolic markers, with elevation of tissue lactate and lactate/pyruvate ratio detectable by clinical microdialysis. However, the multimodality monitoring or imaging of cerebral blood flow (CBF), oxygen extraction fraction, and tissue oxygen may reveal variations in pathophysiology, which could be treated with different therapeutic approaches.

Increased energy demand may be the consequence of seizures, which may be nonconvulsive and only detectable by electroencephalography (EEG) (Ronne-Engstrom and Winkler, 2006; Olivecrona et al., 2009; Vespa et al., 2010) or fever (Sacho et al., 2010; Li and Jiang, 2012; Bao et al., 2014). Recent interest has focused on the role of cortical spreading depression (CSD; Fig. 3), which causes profound depolarization of cortical tissue, and is associated with worse outcomes (Hartings et al., 2011a). Most literature on CSD has focused on electrocorticographic (ECoG) detection, but there is increasing evidence that scalp surface EEG may provide clues to its presence (Hartings et al., 2014). Restoration of membrane potential following CSD is hugely energy demanding, and may be associated with prolonged tissue hypoxia (Takano et al., 2007). While the classic literature has focused on oxygen deficiency in the context of reduced substrate delivery, there is increasing appreciation that metabolic crisis may also arise from inadequate glucose delivery, or an inability to use glucose. Even low-normal blood sugars (e.g., in the context of tight glycaemic control) may result in low brain tissue glucose (Oddo et al., 2008; Meierhans et al., 2010), especially in abnormal tissue (Magnoni et al., 2012), and low brain glucose is an independent driver of CSD (Parkin et al., 2005) and of poor outcome (Vespa et al., 2003).

Vasogenic edema, arising from breakdown of the BBB (Shlosberg et al., 2010; Alves, 2014), is commonly seen in perilesional regions, and in some patients may result in generalized brain swelling. In animal models, BBB breakdown is a biphasic process, with an initial transient leak occurring soon after impact, and a subsequent secondary phase hours to days after TBI. This sequence is less clearly recognizable in clinical TBI. The mechanisms responsible for BBB leak include oxidant injury and inflammation (see below), and recent interest 


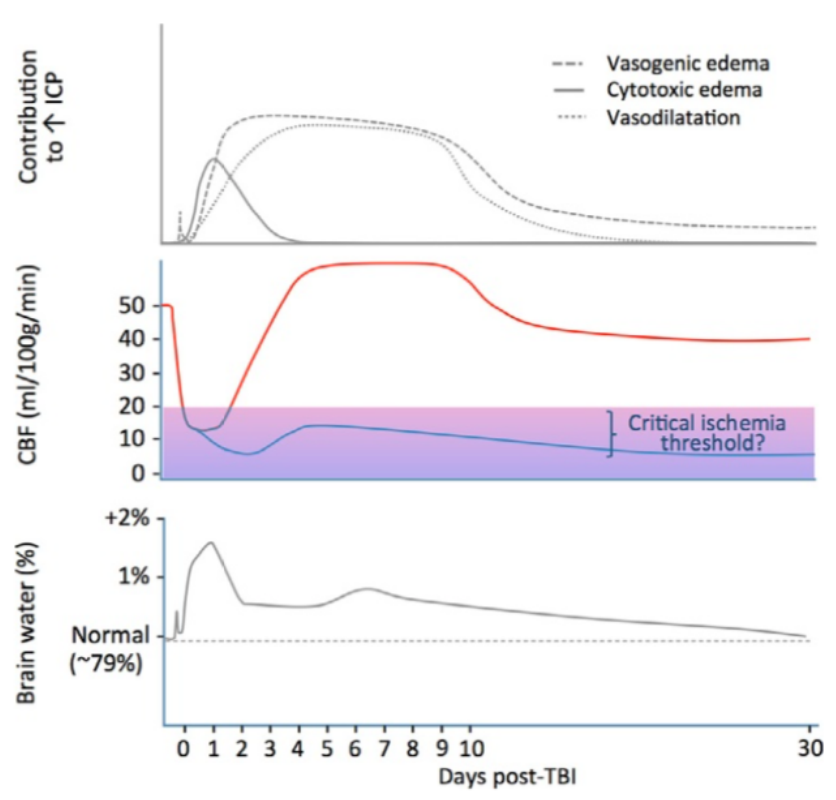

Figure 1: Conceptual diagram of time-varying changes in physiology in traumatic brain injury (TBI) (top panel) and their contribution to increases in brain water (lower panel), and to intracranial hypertension (middle panel). The depicted changes in physiology are based on a consensus from human and experimental research data. ICP, intracranial pressure; CBF, cerebral blood flow.

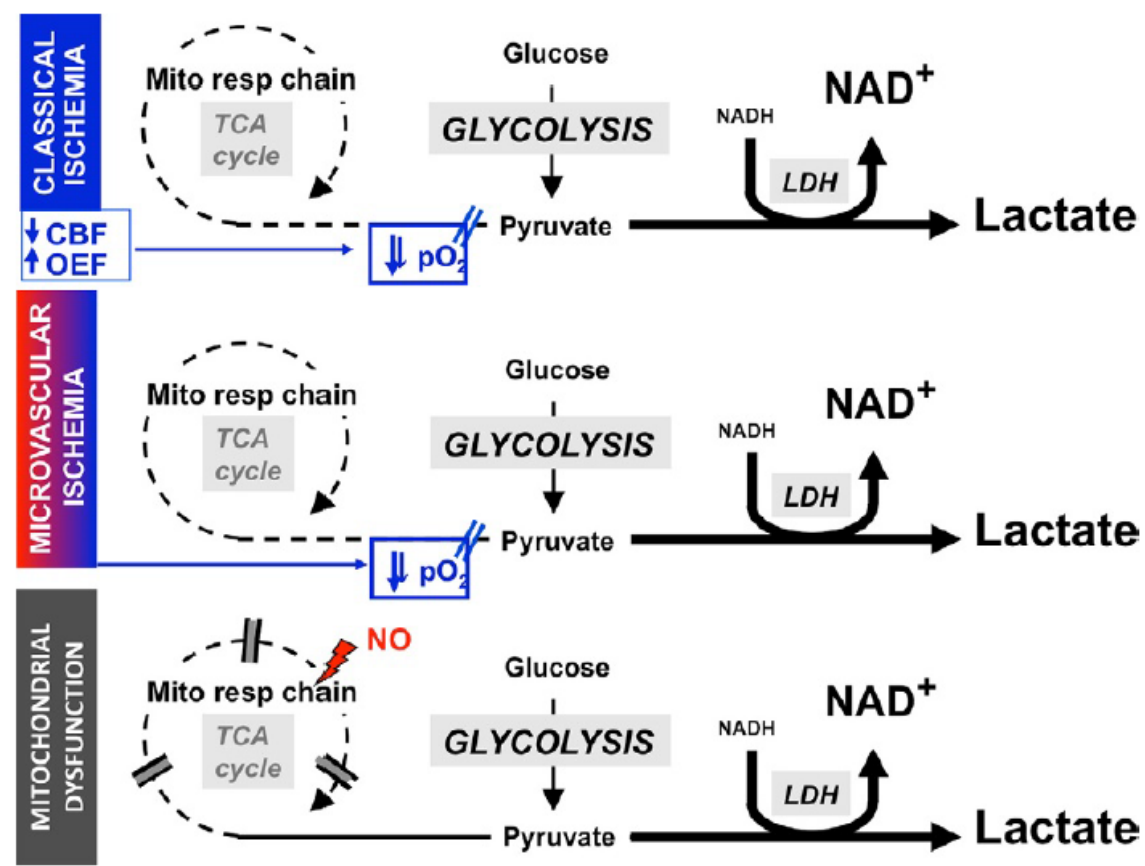

Figure 2: Pathophysiology of multiple mechanisms of energy failure in traumatic brain injury. The downstream metabolic effects (elevations in lactate and lactate/pyruvate ratio) are common to all three, but a reduced cerebral blood flow $(\mathrm{CBF})$, high oxygen extraction fraction $(\mathrm{OEF})$, and a low brain tissue $p \mathrm{O}_{2}\left(P b t \mathrm{O}_{2}\right)$ characterize classic ischaemia, while microvascular ischaemia only shows the reductions in $P b t \mathrm{O}_{2}$. Neither OEF nor $P b t \mathrm{O}_{2}$ is abnormal in mitochondrial failure, although low $\mathrm{PbtO} \mathrm{O}_{2}$ may unmask functional mitochondrial abnormalities due to high levels of nitric oxide (NO), which competes with oxygen at the mitochondrial respiratory chain. TCA, tricarboxylic acid; LDH, lactate dehydrogenase. 

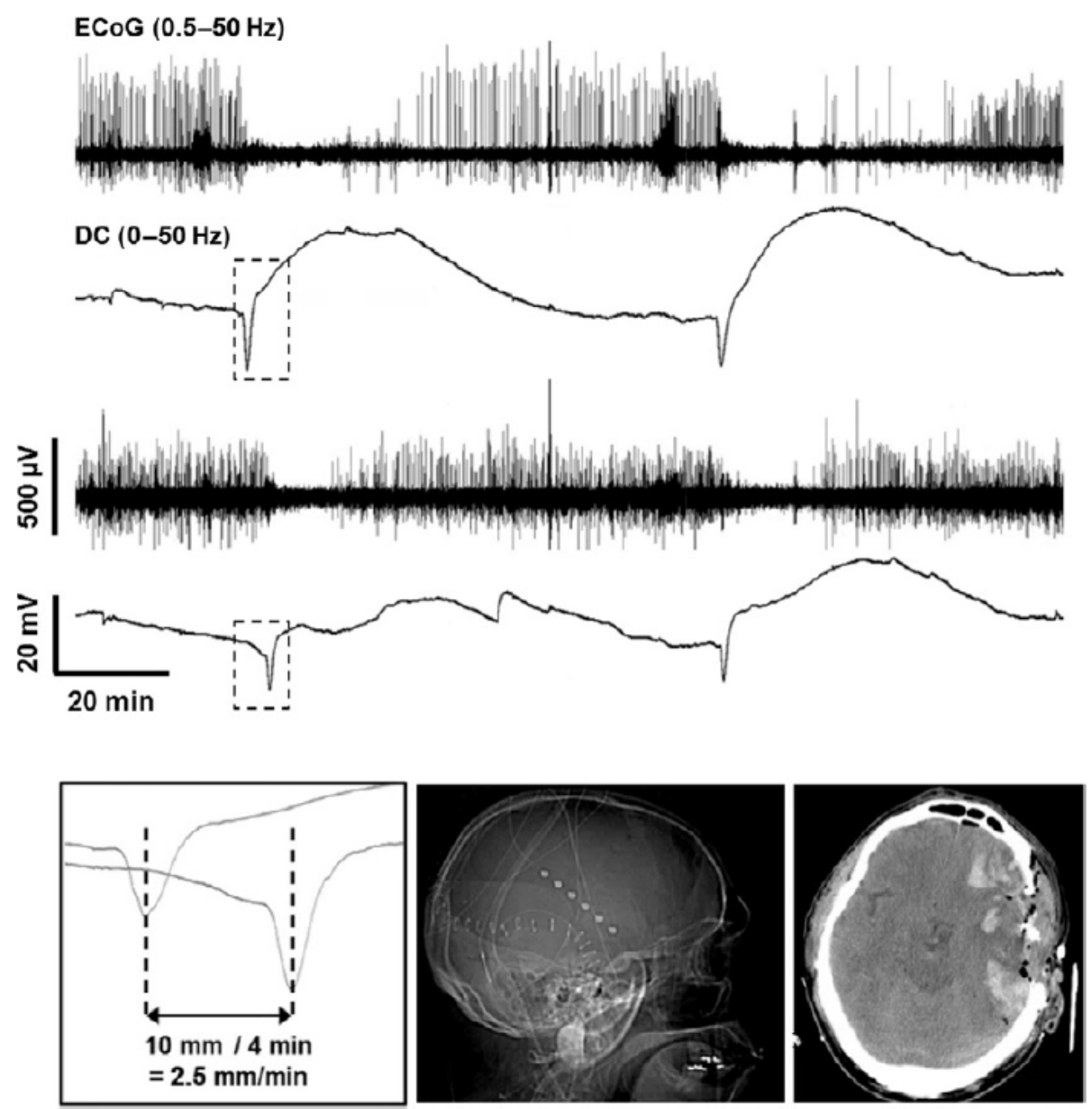

Figure 3: Electrocorticographic (ECoG) recordings from a 61-year-old male following a traumatic brain injury (TBI) from a motorcycle accident. The patient underwent decompressive surgery after enlargement of left frontal and temporal contusions that resulted in a drop in Glasgow Coma Scale from 14 to 11. At surgery, an electrode strip was placed on the left superior temporal gyrus. A total of 89 spreading depolarizations were observed in 5 days of ECoG monitoring. The upper and middle panel show bandpass-filtered $(0.5-50 \mathrm{~Hz}) \mathrm{ECoG}$ and direct current (DC) signal from two adjacent electrodes, $10 \mathrm{~mm}$ apart, in a cortical strip array, from a patient 26 hours after TBI. The onset of the cortical spreading depolarization episode (denoted by reduction in ECoG activity coupled with negative wave in DC potential) has different start times in the two electrodes. Superimposition of the two DC signals (bottom panel, left) shows a propagation rate of $2.5 \mathrm{~mm} / \mathrm{min} \mathrm{between}$ the two electrodes. The images on the middle and right in the lower panel show a lateral image of the skull showing the location of the ECoG strip, and the postoperative computed tomography (CT) appearances on X-ray CT. The patient eventually had an outcome graded as lower severe disability on the extended Glasgow Outcome Scale. (Data and images courtesy of Dr. Jed Hartings, University of Cincinnati.) 
has focused on the role of the sulfonylurea receptor in generating microvascular failure and BBB breakdown (Simard et al., 2012). Low-grade BBB leak may persist for decades after TBI (Hay et al., 2015).

\subsection{Abnormalities in vasomotor tone and reactivity}

Classically, CBF has been reported to exhibit a triphasic behaviour (Martin et al., 1997) following TBI (Fig. 1), with early reductions in blood flow within the first 12-24 hours postinjury (Bouma et al., 1991, 1992). Physiological imaging with positron emission tomography (PET) demonstrates that this is more prominent in the vicinity of contusions and underlying SDHs, and that, in many cases, these CBF reductions represent true ischaemia rather than appropriately coupled hypoperfusion in regions of low metabolic demand (Coles et al., 2004). At later points, CBF increases and may reach supranormal levels (Kelly et al., 1996; Coles et al., 2007). Again, PET imaging shows that at least some of this is true hyperaemia (i.e., CBF in excess of demand). Such abnormal vasomotor tone may be responsible for brain swelling by causing pathological vasodilatation. While a subsequent phase of late CBF reduction due to vasospasm is sometimes seen, the incidence is unclear, though some groups suggest that this may be an underestimated contributor to pathophysiology (Romner et al., 1996; Lee et al., 1997; Oertel et al., 2005).

These time-varying haemodynamic responses also define potential windows for treatment that address each of the underlying processes. However, patients vary enormously, and different mechanisms responsible for intracranial hypertension may operate concurrently even within a single individual at different time points. However, the discussion above provides a conceptual framework for selection of initial "best-guess" therapies in individuals, which can be refined in the light of data from multimodality monitoring.

TBI patients commonly show loss of vascular reactivity to perfusion pressure, and, less commonly, to changes in $\mathrm{PaCO}_{2}$ (Newell et al., 1997; Lee et al., 2001). Both these derangements are indicators of worse prognosis. However, in patients in whom autoregulation is preserved, the autoregulatory range of cerebral perfusion pressure (CPP) over which CBF is maintained may be reduced and/or shifted from the normally accepted 50-150-mmHg range. This altered range of autoregulation can be identified using bedside monitoring of ICP and CPP, and there is increasing evidence that maintenance of CPP at or close to the optimal range for autoregulation (often termed CPPopt) (Steiner et al., 2002; Aries et al., 2012) is associated with improved outcomes (see later).

\section{Clinical presentation}

TBI presentation can be highly varied and may coexist with a diverse range of extracranial pathology. Severity has traditionally been classified in terms of postresuscitation Glasgow Coma Scale (GCS) (Teasdale and Jennett, 1974), with severe TBI being defined as GCS8. Although the GCS has stood the test of time (Teasdale et al., 2014), it has some shortcomings in practice. Alternatives have been proposed to overcome some of these difficulties. For example, the Full Outline of UnResponsiveness (FOUR) score (Wijdicks et al., 2005) has advantages in terms of incorporating pupillary reflexes (an important outcome predictor after TBI) and other brainstem reflexes. The respiratory pattern is also used as a scoring variable, but may be less informative of neurological state if the $\mathrm{PaCO}_{2}$ is low in the fully mechanically ventilated patient, since spontaneous ventilatory drive may be suppressed. Adjustment of the ventilator is needed to asses for ventilatory drive of the patient. The FOUR score has been shown to perform comparably to the GCS in TBI (Sadaka et al., 2012; Okasha et al., 2014; Kasprowicz et al., 2016; Nyam et al., 2017).

Nevertheless, the use of any coma score in the definition of TBI severity is questionable; it is well known that many very different intracranial injuries with diverse outcomes may lead to the same GCS (Saatman et al., 2008). If one studies patients in the ultra-early prehospital setting, brief periods of unconsciousness are common even after more trivial head injuries. Furthermore, with the increasing availability of advanced prehospital intervention, the resuscitation of, for example, a hypoxic and hypovolaemic patient may occur simultaneously with intubation, so that a true postresuscitation GCS is never obtained. Finally, some patients who are fully conscious at the scene may still go on to die as a result of their injuries (Reilly et al., 1975), which demonstrates that the primary injury itself does not entirely account for mortality.

Hypotension (generally as a result of extracranial haemorrhage) and hypoxia (as a result of aspiration, pulmonary injury, or airway obstruction) frequently coexist in the early phase of TBI (Stocchetti et al., 1996). Both of these factors have been repeatedly shown to be key independent determinants of survival (Chesnut et al., 1993; Fearnside et al., 1993; Hill et al., 1993; Murray et al., 2007; Krishnamoorthy et al., 2015), likely in a dose dependent and perhaps synergistic way (Manley et al., 2001; McHugh et al., 2007). The precise threshold for harmful early hypotension is not known, but there is evidence injury may occur substantially above the thresholds used in previous studies, where hypotension has been considered as systolic blood pressures below $90 \mathrm{mmHg}$ (Butcher et al., 2007).

Both hypoxia and hypotension are potentially remediable/ preventable in the ultra-early phase, and advances in prehospital trauma care are changing the presentation of TBI to hospitals. These factors are also determinants 
of survival in trauma patients irrespective of TBI. The CRASH-2 study demonstrated a survival benefit for early administration of tranexamic acid in bleeding trauma patients (CRASH-2 trial collaborators et al., 2010). A nested study within CRASH-2 (Perel et al., 2012) examining the subgroup of patients with mild, moderate, or severe TBI and abnormal computed tomographic (CT) brain findings found a trend towards reduction in haemorrhage growth, fewer ischaemic lesions, and fewer deaths when tranexamic acid was administered, although none of these were statistically significant. These findings have formed the basis for CRASH-3, a trial of tranexamic acid in TBI with intracranial haemorrhage (Dewan et al., 2012).

The incidence of intracranial hypertension at the time of presentation to hospital and in the prehospital phase is unknown, but likely to be low, except in patients with surgical intracranial space-occupying lesions. Seizures are also commonly reported by bystanders and prehospital teams, although again, the true incidence is unknown. It is not clear how often various abnormality movements, such as posturing, are mistaken for seizures. Furthermore it is not known what fraction of events can be attributed to the brain injury or are instead a result of hypoxia from transient airway obstruction or caused by hypotension, and therefore it is difficult to exactly specify the prognostic significance of this finding.

\section{$5 \quad$ Imaging}

Neuroimaging is used for diagnosis, therapy selection (especially for surgical interventions), and prognostication. $\mathrm{CT}$ and MRI both have their specific place, but their relative roles are currently in some flux.

At presentation, especially with more severe grades of TBI, imaging is used to detect and quantify injury, identify treatable lesions, and guide surgical interventions. Multidetector CT remains the technique of choice in this context, allowing rapid integrated examination of the head and cervical spine (Parizel et al., 2005), and detection and evaluation of surgically treatable lesions, both by quantifying lesion volume, and its impact in terms of space occupation (by identifying the extent of midline shift, and sulcal and cisternal effacement). The detection of intracranial haematomas which do not require evacuation may prompt intracranial pressure (ICP) monitoring, or trigger serial CT for detecting haematoma or contusion expansion, or for identifying development of hydrocephalus (most commonly with subarachnoid or intraventricular haemorrhage). Current surgical guidelines recommend surgery based primarily on CT findings, with craniotomy recommended for subdural or extradural haematomas larger than $30 \mathrm{~mL}$ or associated midline shift exceeding $5 \mathrm{~mm}$; and for parenchymal haematomas exceeding $20 \mathrm{~mL}$ in noneloquent cortex (see Bullock et al., 2006, and subsequent articles in the same supplement).

Over the past decade, substantial improvements in CT technology have enhanced its role (Rostami et al., 2014). Additional data available from fast multidetector CT include CT angiography (to exclude vascular injury), and increasing use of mobile CT scanners reduces the risks of transport in unstable patients (Carlson and Yonas, 2012; Agrawal et al., 2016). While CT perfusion studies can provide parametric images of CBF, cerebral blood volume, and mean transit time alongside CT angiography and structural imaging, this technique is still primarily confined to research studies.

$\mathrm{CT}$ as a sole technique does not characterize TBI completely (Fig. 4), particularly with reference to posterior fossa lesions, TAI, and early ischaemia, and MRI provides complementary information in this context (Altmeyer et al., 2016). Conventional structural MRI can provide better characterization of parenchymal abnormalities, especially in the posterior fossa, and increases the sensitivity for detection of TAI (Mannion et al., 2007). The microvascular shearing associated with TAI may be visible as microhaemorrhages on CT, but the sensitivity and interobserver variability of this finding are poor (Harrison et al., 2013). CT has some prognostic content, perhaps best characterized by the Marshall grading system or Rotterdam CT Score (Maas et al., 2005), but is imperfect at predicting outcomes in patients with moderate and severe TBI, $20 \%$ of whom have normal or near-normal admission CT appearances, but who may still have poor outcomes because of undetected DAI. Conversely, rapid surgical evacuation combined with high-quality intensive care can deliver good outcomes in patients with very abnormal initial CT scans, including those with large intracranial haematomas. MRI may provide increased prognostic capacity in this setting, over and above that provided by clinical and laboratory features and CT (Moen et al., 2014).

Diffusion-weighted MRI can directly image axonal shearing and map such injury (Newcombe et al., 2007), but an additional strength of MR in detecting acute TAI lies in its exquisite sensitivity for detecting microhaemorrhages that accompany axonal lesions, especially with a new generation of $\mathrm{T} 2{ }^{*}$-sensitive sequences. Different MR sequences show specific patterns of lesion evolution, and while fluid-attenuated inversion recovery (FLAIR) and diffusion-weighted imaging may predict outcome early in the acute phase, they appear to lose conspicuity over time, and may underestimate the extent of injury at 3 months (Moen et al., 2012). Susceptibility weighted imaging sequences, on the other hand, show good lesion detectability at 3 months, only fading by 12 months postinjury. Persistent neurological symptoms may be the result of subtle microstructural alterations, such as TAI, which are often demonstrated at autopsy, but have remained undetected by conventional antemortem imaging in the past. 


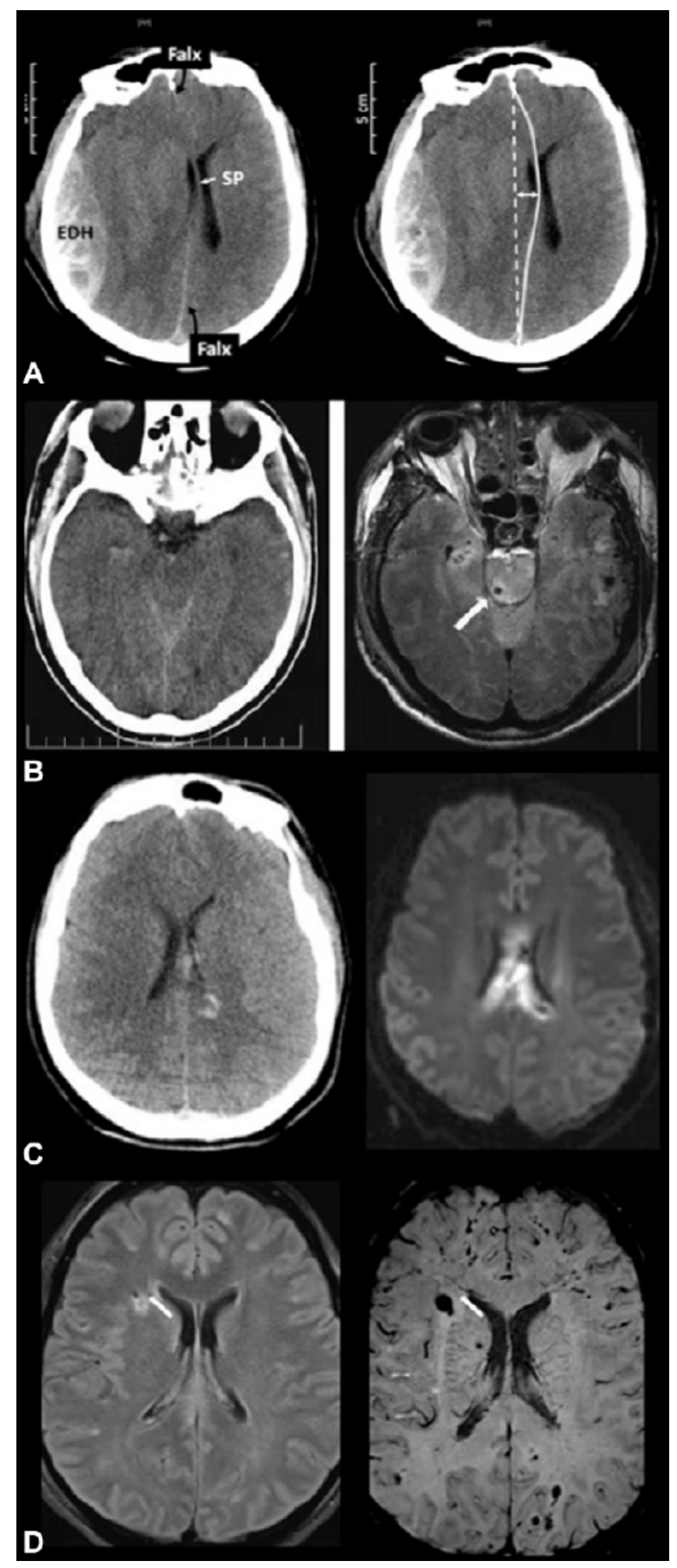

Figure 4: Imaging in traumatic brain injury. (A) Computed tomography (CT) remains the imaging modality of choice for the demonstration of surgical lesions, such as this extradural haematoma (EDH), and demonstration of their spaceoccupying impact in terms of midline shift of the falx cerebri and septum pellucidum (SP). (B) However, CT is poor at imaging the posterior fossa - see the brainstem lesion that is not seen on CT (left) but clearly demonstrated by magnetic resonance imaging (MRI: right). Also note the detail of microstructural abnormality in the medial right temporal contusion on MRI, which is not seen on CT. (C) Diffusion-weighted MRI (on the right) can show traumatic axonal injury (here in the corpus callosum) with greater sensitivity than CT (on the left). (D) Susceptibility-weighted imaging (right) shows petechial haemorrhages associated with traumatic axonal injury in peripheral white matter more conspicuously and with greater sensitivity than conventional MR sequences such as fluid-attenuated inversion recovery (left). 


\begin{tabular}{|c|c|c|c|c|}
\hline Biomarker & Source & Phase & Type & Limitations \\
\hline S100-B & Blood & Acute & $\begin{array}{l}\text { Glial/blood-brain } \\
\text { barrier change }\end{array}$ & $\begin{array}{l}\text { Not central nervous } \\
\text { system-specific }\end{array}$ \\
\hline $\begin{array}{l}\text { Neuron-specific } \\
\text { enolase }\end{array}$ & Blood & Acute & Neuronal & $\begin{array}{l}\text { Present in red blood cells, } \\
\text { elevated with haemolysis }\end{array}$ \\
\hline $\begin{array}{l}\text { Glial fibrillary } \\
\text { acidic protein }\end{array}$ & Blood & Acute & Glial & \\
\hline UCH-L1 & Blood & Acute & Neuronal & Raised in gut neoplasia \\
\hline $\begin{array}{l}\alpha \text { II-Spectrin } \\
\text { breakdown products }\end{array}$ & Blood & Acute & Axonal & Under investigation \\
\hline $\begin{array}{l}\text { Neurofilament } \\
\text { proteins }\end{array}$ & $\begin{array}{l}\text { Cerebrospinal } \\
\text { fluid }\end{array}$ & $\begin{array}{l}\text { Acute/ } \\
\text { subacute }\end{array}$ & Axonal & Under investigation \\
\hline $\begin{array}{l}\text { Tau, phospho-tau, } \\
\text { amyloid } \beta\end{array}$ & $\begin{array}{l}\text { Cerebrospinal } \\
\text { fluid (blood) }\end{array}$ & $\begin{array}{l}\text { Acute/ } \\
\text { chronic }\end{array}$ & Neurodegeneration & Under investigation \\
\hline Cytokines & $\begin{array}{l}\text { Blood, cerebrospinal } \\
\text { fluid, microdialysate }\end{array}$ & $\begin{array}{l}\text { Subacute/ } \\
\text { chronic }\end{array}$ & $\begin{array}{l}\text { Innate immune } \\
\text { response }\end{array}$ & $\begin{array}{l}\text { Under investigation. } \\
\text { Not central nervous } \\
\text { system-specific }\end{array}$ \\
\hline Autoantibodies & Blood & Chronic & $\begin{array}{l}\text { Adaptive immune } \\
\text { response }\end{array}$ & $\begin{array}{l}\text { Under investigation. } \\
\text { Clinical relevance unclear }\end{array}$ \\
\hline
\end{tabular}

Table 2: Protein biomarkers in traumatic brain injury. Summarized from several publications (Pelinka et al., 2004; Vos et al., 2004; Honda et al., 2010; Bohmer et al., 2011; Mondello et al., 2011, 2012; Papa et al., 2012; Stein et al., 2012; Okonkwo et al., 2013; Diaz-Arrastia et al., 2014; Korley et al., 2016).

Logistic and clinical considerations, however, limit use of MRI, particularly in the acute setting. The need to exclude contraindications to MRI in the comatose patient, the requirement to change to dedicated MRcompatible monitoring, and the longer duration of MR studies mean that the use of MR in the acute setting is less common than its capabilities might suggest. As a consequence, the most common clinical (as opposed to research) indication for MR studies in TBI in the ICU is to explain clinical progress that is worse than expected based on the $\mathrm{CT}$ and to evaluate prognosis in patients who fail to emerge from coma following cessation of sedation (Galanaud et al., 2012; Stevens et al., 2014).

\section{Biomarkers}

There has been substantial recent interest in the use of protein biomarkers in blood, and to a lesser extent in cerebrospinal fluid (CSF), to aid in the diagnosis, monitoring, and prognostic assessment of TBI (Kawata et al., 2016; Kulbe and Geddes, 2016). The key proteins that are currently in clinical use or evaluation are listed in Table 2, but only one of these (S100-B) is part of a consensus guideline pathway, where it has been used to stratify patients with mild TBI for CT imaging at presentation (Unden et al., 2015).

At first sight, a diagnostic TBI marker may appear to have limited relevance in the ICUsetting, since the severity of TBI which predicates critical care would be easily detectable. Indeed, the major application of diagnostic biomarkers has been in the emergency room, in diagnosing mild TBI, or assessing the need for neuroimaging (Kulbe and Geddes, 2016). However, such data may also be critically relevant for the intubated patient admitted with multiple trauma, where the CT scan is not impressive, but the presence of extracranial injuries precludes reversal of sedation and full neurological assessment. In such a context, increases in blood levels of protein biomarkers could trigger repeat neuroimaging after an interval, placement of ICP monitoring, and more rigorous attention to cardiorespiratory targets.

Many of these diagnostic biomarkers have also been used for monitoring progress with severe TBI in the critical care setting. Perhaps the best-characterized biomarkers in this context are S100-B, glial fibrillary acidic protein (GFAP), and neuron-specific enolase, measured in blood or CSF, which have been shown to correlate with secondary insults such as lesion expansion and brain hypoxia. However, the available literature suggests that such late elevations may document the occurrence of secondary insults, rather than warn of their impending likelihood. This does not detract from the prognostic impact of such serial measurement (perhaps using area-under-the-curve approaches to quantifying injury). However, this makes it difficult to understand how integration of protein biomarker measurement into a management algorithm could refine or expedite interventions aimed at preventing or mitigating these events. While not in common clinical use, the measurement of mediators that drive tissue injury may hold more promise in the future. Elevations in IL-8, TNF- $\alpha$, or complement fractions may provide warning of activation of an injury process before it has time to fully impact on tissue fate, or by stratifying patients for therapy with specific biological modulators. 
Finally, levels of single biomarkers, or combinations of biomarkers, have been used to refine assessment of prognosis in TBI. There is reasonable evidence that measurements of S100-B, GFAP, and UCH-L1 could provide prognostic information, and that the combination of GFAP and UCH-L1 may perform better than a single biomarker. Perhaps even more relevant, there is now emerging evidence that the addition of biomarker data to well-established clinical outcome prediction schemes can provide added value, and refine prognostication.

\section{Bedside neurodiagnostics and monitoring}

The fundamental basis for assessment of patients with TBI, whenever possible, remains the clinical examination (Riker et al., 2014). Both the GCS and the FOUR score provide well-validated schemes for following disease evolution and resolution, particularly in nonsedated patients. Even in sedated patients, attention to brainstem reflexes and clinical signs can add value to the assessment (Sharshar et al., 2014). However, in some patients, the clinical examination may be inadequate and additional monitoring may be needed to provide early warning of the development and mechanisms of physiological deterioration (Oddo et al., 2016).

A fundamental goal of neurointensive care is to ensure that oxygen and metabolic substrate delivery is appropriate to prevent neuronal injury. Reduction in CBF in response to rising ICP is perhaps the best-known mechanism by which supply can be threatened and motivates the widespread use of ICP measurement and CPPguided therapy, and has formed the basis of widely adopted international guidelines (Brain Trauma Foundation, American Association of Neurological Surgeons, Congress of Neurological Surgeons, 2007a). Measurement of ICP alone, however, is a somewhat blunt instrument (Hutchinson et al., 2013). It does not allow the clinician to determine whether a physiological threshold has been reached at which oxygen supply, for example, has become inadequate; this may depend on many factors. Furthermore, in reality there are many other pathological states that may cause supply-demand imbalance apart from perfusion embarrassment due to raised ICP/low CPP. A recent randomized controlled trial of ICP monitoring directed treatment failed to show a survival benefit (Chesnut et al., 2012). However, a recent consensus-based interpretation of this study highlighted our inability to identify critical thresholds for harm from intracranial hypertension, calibrate the dose of intracranial hypertension for individual patients (Vik et al., 2008), and personalize interventions on this basis (Chesnut et al., 2015). For example (see earlier section on pathophysiology), impaired oxygen diffusion, mitochondrial dysfunction or high cerebral metabolic rate of oxygen from inadequate sedation or seizures may all lead to failure of aerobic metabolism when this is already precarious. Ideally we would make a full diagnosis of the dominant mechanism(s) for energy failure in a particular patient and at a particular time. This would allow precision therapeutic strategies (National Research Council Committee on A Framework for Developing a New Taxonomy of Disease, 2011) and minimize harm from the inevitable side-effects of choosing treatments that are less appropriate under the specific circumstances.

A multimodality approach integrating data from a variety of implantable sensors is needed to formulate a full picture of dominant pathobiology in real time (Le Roux et al., 2014; Hutchinson et al., 2015). Such bedside technology works in real time, allowing the physician to assess the response to therapies. However multimodality sensing is necessarily insensitive to focal pathology distant to the site of the probe.

The availability of routine CT imaging provides invaluable information on structural pathology. More advanced imaging technologies exist that can provide detailed comprehensive spatial assessment of CBF, substrate delivery, connectivity, and functional or metabolic abnormalities (see earlier section) (Amyot et al., 2015). Whilst imaging is invaluable and sensitive to focal pathology (unlike bedside techniques), logistical constraints and concerns about radiation burden with repeated imaging mean that it can provide only snapshots. In reality the clinician must combine all these techniques for the most comprehensive assessment of cerebral pathology.

\subsection{Bedside multimodality monitoring}

Invasive ICP monitoring is widely employed in the management of severe TBI in intensive care (Chesnut et al., 2015). A variety of technologies exist, amongst which direct CSF pressure measurement via an external ventricular drain is the most accurate method and has the additional advantage of permitting CSF drainage to reduce ICP. Intraparenchymal pressure transducers based on miniature resistive or fiberoptic strain gauge technologies are a popular alternative, as they have a lower infection risk than external ventricular drains, are simpler to introduce, and are sufficiently small that they may be introduced through a burrhole, either alone or in combination with other multimodality sensors through a multiple-lumen bolt (Hutchinson et al., 2000) (Fig. $5)$.

Brain oxygenation (Oddo et al., 2014) can be assessed by the measurement of tissue oxygen tension $\left(P b t \mathrm{O}_{2}\right)$ either electrochemically (Licox, Integra Lifesciences, Plainsboro, NJ, USA)) or by the oxygen-dependent fluorescence quenching (Neurovent-PTO, Raumedic, Helmbrechts, Germany). $\mathrm{PbtO}_{2}$ is a spatial average of oxygen partial pressure and is determined by the balance between oxygen supply and consumption, but also by diffusion, which may be impaired after TBI (Rosenthal et al., 2008). 


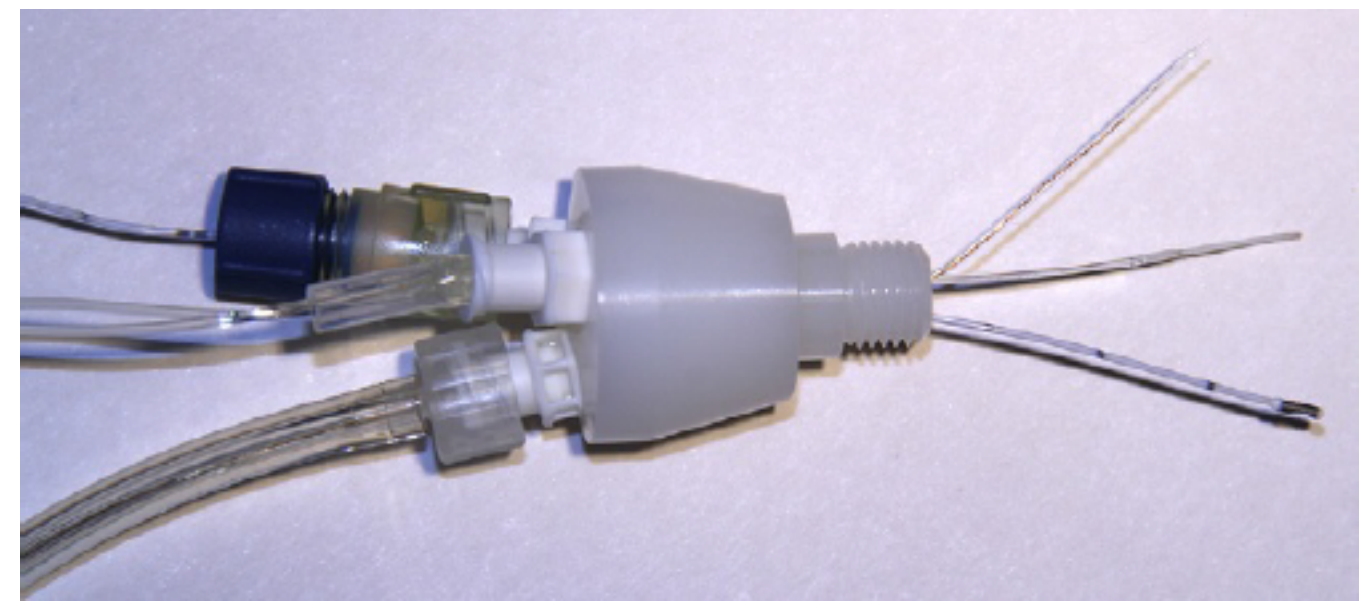

Figure 5: "Triple bolt" for introducing invasive multimodality monitoring. The bolt is placed via a frontal burrhole (noneloquent and generally nondominant brain to minimize the functional consequences of haemorrhagic complication). Emerging on the right hand side are (top to bottom): Licox $P b t \mathrm{O}_{2}$ probe, microdialysis, and Codman intraparenchymal intracranial pressure probe.

Cerebral microdialysis (Hutchinson et al., 2015) is less well established, but is nonetheless employed clinically in a number of neuroscience critical care centres. A crystalloid perfusate is passed through a coaxial intraparenchymal catheter (Fig. 6) with a semipermeable membrane so that the effluent reflects brain chemistry. Flow rates are a tradeoff between reliable chemical recovery and providing sufficient effluent for analysis on a clinically meaningful timescale. Typically, hourly measurements are made using an automated bedside colorimetric assay. Typical clinical catheters have a cutoff of $20 \mathrm{kDa}$, and are suitable for the recovery of a range of small molecules. The lactate:pyruvate ratio (LPR) and brain tissue glucose have received most application clinically. LPR is an assay for anaerobic glucose utilization, and this has been demonstrated to have prognostic significance (Timofeev et al., 2011). Brain tissue glucose is sensitive to ischaemia/hyperaemia, and the balance between supply and hyper-/hypometabolism and low brain glucose concentrations may be an important driver of secondary injury (Rostami et al., 2014).

Whilst complications from invasive monitoring are rare, they can occasionally be devastating. This has motivated attempts to find noninvasive alternatives. Noninvasive ICP measurements based on a variety of techniques are being developed and may be promising.

Noninvasive determination of cerebral oxygenation (Oddo et al., 2014) is possible by near-infrared spectroscopy (NIRS). Biological tissue transmits near-infrared light well. By placing optodes on the scalp and determining the transmission at different wavelengths and distances, it is possible to estimate the haemoglobin oxygen saturation (as well as haemoglobin concentration and other chromophore concentrations depending on the design of the equipment). Since much of the blood volume in the brain is venous, NIRS is thought to be largely (but not exclusively) sensitive to oxygen extraction and therefore can be used to determine critical oxygen supply/demand mismatch. However contamination of the signal from extracranial blood can complicate NIRS interpretation, particularly in adults (the optical path must traverse the scalp, for example).

Patients with TBI are at high risk of seizures, including in the early stages postinjury. Continuous EEG (cEEG) has demonstrated a high prevalence (up to one-third: Ronne-Engstrom and Winkler, 2006) of nonconvulsive seizures (NCS), particularly in patients with penetrating injuries, depressed skull fractures, or large haematomas. On balance, it is uncertain whether prophylactic treatment with antiepileptic medicines is beneficial; practices vary accordingly. Nevertheless persistent seizures are predictive of poor outcome (Vespa et al., 2010) and seizure activity is undesirable because of its deleterious effects on metabolic rate and ICP (Vespa, 2016), which are plausible mechanisms for secondary injury. Thus cEEG has become an important monitoring strategy in neurocritical care for detecting NCS and ensuring the adequacy of sedation (Claassen et al., 2014).

More recently there has been growing research interest in the use of invasive ECoG or depth electrode to detect cortical spreading depolarizations in TBI (Strong et al., 2002; Fabricius et al., 2006). These are slow-moving mass depolarizations of neurons that are associated with massive ionic and osmotic fluxes and energy crisis in metabolically precarious tissue (Hinzman et al., 2016). Spreading depolarizations have been repeatedly identified after TBI (Hartings et al., 2011a) and shown to have an independent association with poor outcome (Hartings et al., 2011a, b). Further work to understand the significance of this phenomenon in TBI is required. Nevertheless, the occurrence of spreading depolarizations may be modulated by sedative drugs; for example, ketamine markedly reduces their incidence (Hertle et al., 2012a) and if this proves to be a useful intervention, then ECoG (or a robust noninvasive cEEG correlate (Hartings et al., 2014)) may become an important monitoring modality in the future. 


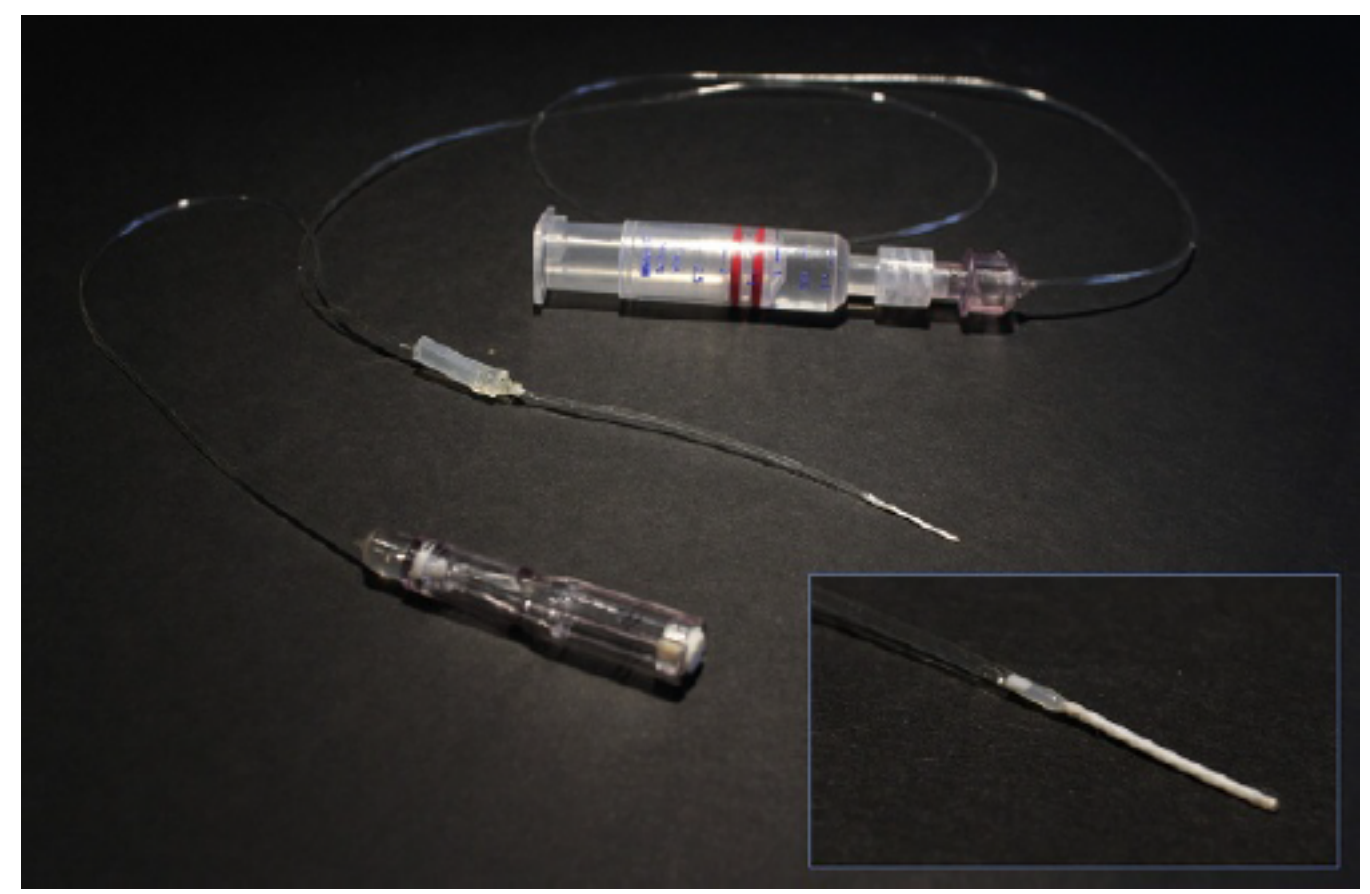

Figure 6: Microdialysis equipment. A syringe pump creates a flow of crystalloid solution through the coaxial semipermeable probe (inset). At typical flow rates of $0.3 \mathrm{~mL} / \mathrm{min}$, good recovery can be obtained and hourly sampling of effluent is possible using a system of removable vials.

Often, combinations of parameters convey useful physiological significance beyond the parameters alone. The simplest is the derived parameter CPP that is calculated automatically from mean arterial pressure (MAP) and ICP, and displayed by most monitors. Another more complex derived parameter that is showing promise as a clinically useful marker of autoregulation is the pressure-reactivity index $(\mathrm{PRx})$. PRx is calculated as the correlation coefficient between a 10-second moving window of MAP and ICP. Autoregulation often fails after severe TBI, so that increases in MAP cause an increase in cerebral blood volume and therefore ICP, rather than the reflex vasoconstriction expected in health. Thus, the correlation between MAP and ICP becomes positive and $\mathrm{PRx}>0$ indicates impaired autoregulation (Fig. 7).

PRx may be automatically calculated in real time by a computer and has clinical significance. Positive PRx has been shown to be an independent predictor of mortality (Sorrentino et al., 2011), and PRx-derived patient-specific thresholds for CPP show a stronger association with outcome than average population values (Lazaridis et al., 2014).

Furthermore, over longer periods of time, PRx often shows a U-shaped relationship with CPP (Fig. 8), reflecting the autoregulatory range (Steiner et al., 2002). This leads to the concept of the optimal CPP (CPPopt), which is the CPP for which PRx is lowest, and therefore for which autoregulation is best preserved. In retrospective observational studies, patients managed below their CPPopt had a higher mortality, whereas those above had worse than expected disability (Aries et al., 2012). High-level evidence for the use of autoregulation as a clinical parameter is lacking, but the optimization of autoregulation may prove to be one further method by which clinicians could seek to personalize CPP targets and balance the harm from either hypo- or hyperperfusion.

The use of multimodality monitoring is supported by a number of guidelines and international consensus statements (Brain Trauma Foundation, American Association of Neurological Surgeons, Congress of Neurological Surgeons, 2007a; Le Roux et al., 2014). Without clear randomized prospective data, normal ranges and treatment thresholds are derived from observational data studying a variety of outcomes and correlates of tissue injury (Table 3). It is misleading to base treatment on any individual parameter: often the concordance or discordance between measurements from different modalities may be just as significant in building up a picture of the dominant physiology. Localized measurements (such as $\mathrm{PbtO}_{2}$ or microdialysis) must be assessed in the knowledge of the probe location, since abnormal values in pericontusional tissue or "healthy" brain will have very different interpretations, and trigger different interventions. 


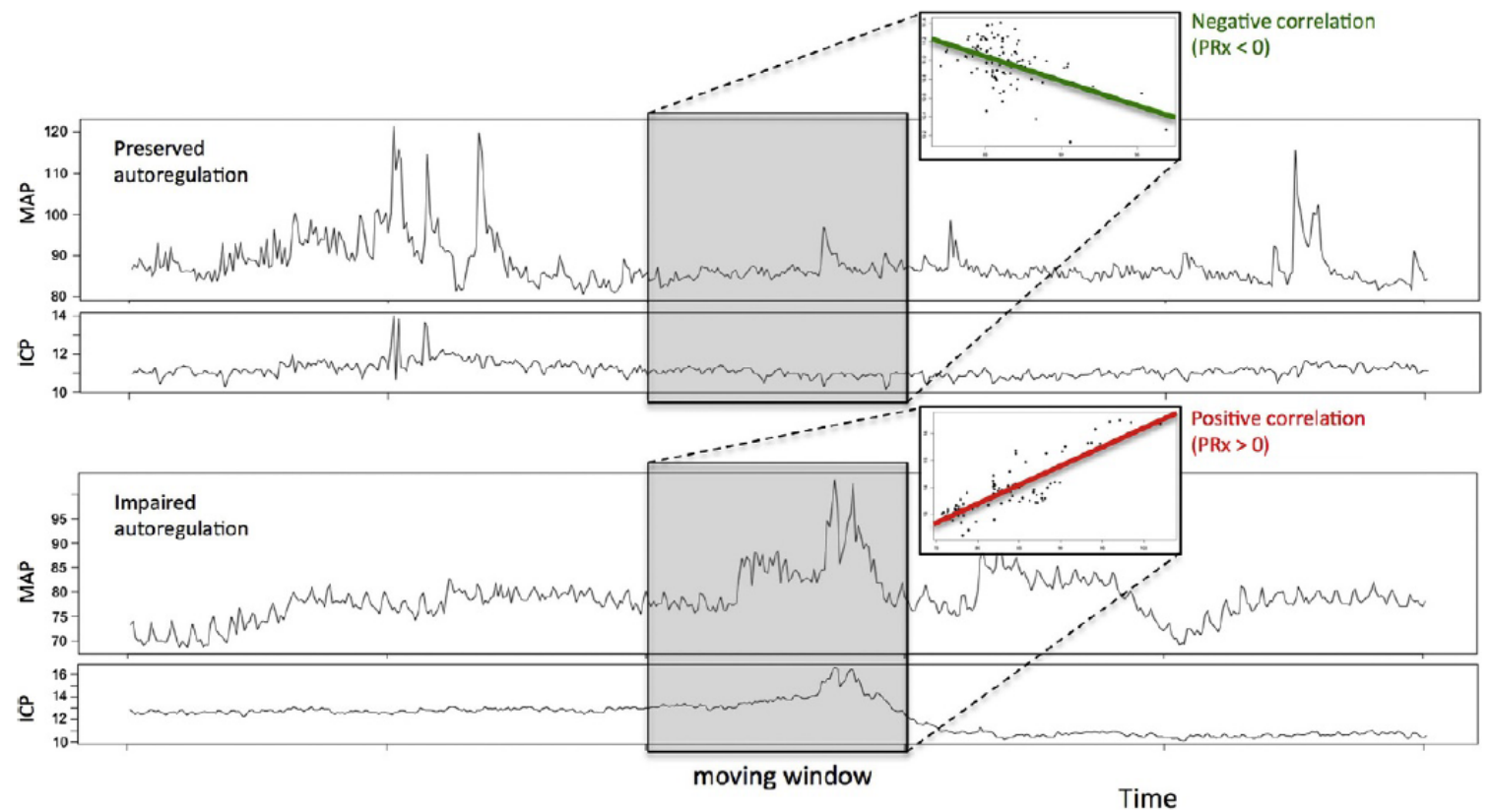

Figure 7: Pressure-reactivity index $(\mathrm{PRx})$ is calculated as the correlation coefficient for a 10-second moving window of mean arterial pressure (MAP) and intracranial pressure (ICP) signals. The upper panel shows a patient in whom autoregulation is preserved and PRx is negative or near zero. In the lower trace, the ICP is pressure-passive as autoregulation is impaired. This is revealed by a $\mathrm{PRx}>0$.

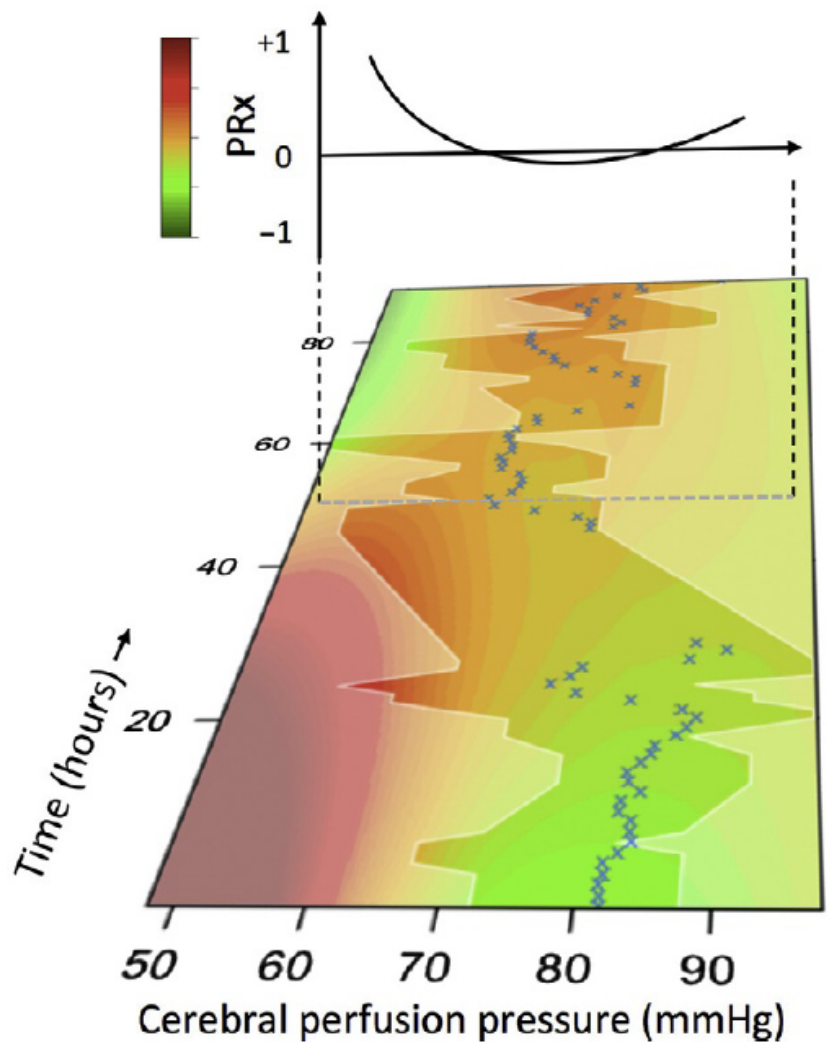

Figure 8: Pressure-reactivity index (PRx) often displays a U-shaped relationship with cerebral perfusion pressure $(\mathrm{CPP})$ over time, reflecting the autoregulatory range. The CPP for which PRx is lowest (CPPopt) is the CPP for which autoregulation is best preserved. 


\begin{tabular}{lllc}
\hline \multirow{2}{*}{ Parameter } & $\begin{array}{l}\text { Threshold for injury/treatment } \\
\text { "Normal" range } \\
\text { (intensive care unit patients) }\end{array}$ & More stringent \\
\hline \hline Intracranial pressure & $<15 \mathrm{mmHg}$ & $20-25 \mathrm{mmHg}$ & $20 \mathrm{mmHg}$ \\
$\mathrm{PbtO}_{2}$ & $30 \mathrm{mmHg}$ & $15-25 \mathrm{mmHg}$ & $<15 \mathrm{mmHg}$ \\
Lactate:pyruvate ratio & $<25$ & $>25$ & $>40$ \\
Brain tissue glucose & $1-2 \mathrm{mmol} / \mathrm{L}$ & $<0.8 \mathrm{mmol} / \mathrm{L}$ & $<0.2 \mathrm{mmol} / \mathrm{L}$ \\
\hline
\end{tabular}

Table 3: Normal ranges and treatment thresholds for common mulitimodality monitoring variables. "Normal" ranges derived from patients with probes placed in structurally normal brain, and no evidence of acute brain injury. Prospective intervention data are not available, so treatment thresholds are inferred from observational heterogeneous outcome data (Le Roux et al., 2014; Rostami, 2014; Hutchinson et al., 2015). The two sets of injury thresholds reflect varying severity of physiological derangement, with more aggressive therapies possibly justified only for more severe abnormalities.

\section{Hospital course and management}

Current intensive care management of severe TBI is based on maintaining physiology so as to minimize secondary insults that may occur, especially over the first few days. Secondary injury may arise as a result of systemic (hypotension, hypoxaemia, hypocapnia, hypo- or hyperthermia, or metabolic) disturbances or intracranial causes (intracranial hypertension, ischaemia, hyperaemia, edema, or haemorrhage) (Chesnut et al., 1993; Jones et al., 1994; Signorini et al., 1999; Macmillan et al., 2001; Manley et al., 2001; Sarrafzadeh et al., 2001; Jeremitsky et al., 2003; Chi et al., 2006; Brenner et al., 2012). The clinical trajectory of TBI varies enormously between patients, as may the impact of comorbidity or extracranial injuries, such that a holistic and individualized approach is essential.

Central to neurocritical care is the control of ICP and maintenance of CPP. Avariety of strategies are available for the nonsurgical management of raised ICP. All are associated with at least some degree of harmful side-effects and a stepwise escalation of therapeutic intensity is prudent. Guidelines have been published (Brain Trauma Foundation, Surgeons, American Association of Neurological Surgeons, Congress of Neurological Surgeons, 2007e) and a protocolized approach is helpful to facilitate timely escalation and de-escalation of therapy.

\subsection{First-line strategies and basic intensive care}

\subsubsection{Ventilatory strategies}

Endotracheal intubation and mechanical ventilation are important to protect the airway in TBI patients with reduced consciousness and may be indicated by the presence of extracranial injury, but are also critical to ensure optimal arterial oxygen and $\mathrm{CO}_{2}$ tension. Carbon dioxide is a potent cerebral vasodilator, and hypercapnia may cause increases in ICP if intracranial compliance is limited. Conversely, hypocapnic vasoconstriction may result in substantial ICP reductions when ICP is very high and/or intracranial compliance is low (Steiner et al., 2005). However, when intracranial hypertension is modest, the effects on CPP are overwhelmed by the associated arteriolar vasoconstriction, which can lead to dangerous ischaemia (Muizelaar et al., 1991; Coles et al., 2002, 2007). Resetting of extravascular $\mathrm{pH}$ with prolonged ventilation in TBI patients may mean that the hypocapniaassociated reduction in ICP is transient, but the detrimental CBF reductions that it causes may persist (Steiner et al., 2004). Consequently, unless the increase in ICP is high enough to present a greater hazard than the cerebral hypoperfusion caused by hyperventilation (as during a plateau wave, for example), ventilation should target levels of $\mathrm{PaCO}_{2}$ that are at the low end of normal. Apart from brief use in emergent settings, more extreme hyperventilation $\left(\mathrm{PaCO}_{2}\right.$ below $30 \mathrm{mmHg}$ ) should only be undertaken with monitoring of $\mathrm{Pbt} \mathrm{O}_{2}$ or jugular bulb saturation. Hypoxia needs to be scrupulously avoided (arterial oxygen saturations $>95 \%$ ), both because of direct hypoxic injury, but also to avoid hypoxic cerebral vasodilatation (and consequent ICP increases), which may occur at oxygenation levels that are acceptable in critically ill patients without neurological injury (Gupta et al., 1997). There is increasing interest in using normobaric hyperoxia to elevate $P b t \mathrm{O}_{2}$ and reduce elevations in lactate and LPR (Beynon et al., 2012). Increases in $\mathrm{PaO}_{2}$ can, in the short term, improve oxygen metabolism (Nortje et al., 2008) and reduce cytotoxic edema (Veenith et al., 2014) in at-risk regions in TBI, and there have been recent phase II trials of both normobaric (Taher et al., 2016) and hyperbaric (Rockswold et al., 2013) hyperoxia suggesting benefit in TBI. However, there is also emerging concern about the potential harm caused by hyperoxia in TBI (Rincon et al., 2014), and widespread use of this intervention should await demonstration of benefit from a substantive randomized clinical trial. Patients who require prolonged endotracheal intubation and ventilation usually undergo tracheostomy. While there are no randomized clinical trials (RCTs) addressing the optimal timing of tracheostomy in TBI patients, accumulating non-RCT evidence suggests that early $(<8$ days) tracheostomy may reduce infection, and accelerate weaning and ICU discharge (Rizk et al., 2011; Wang 


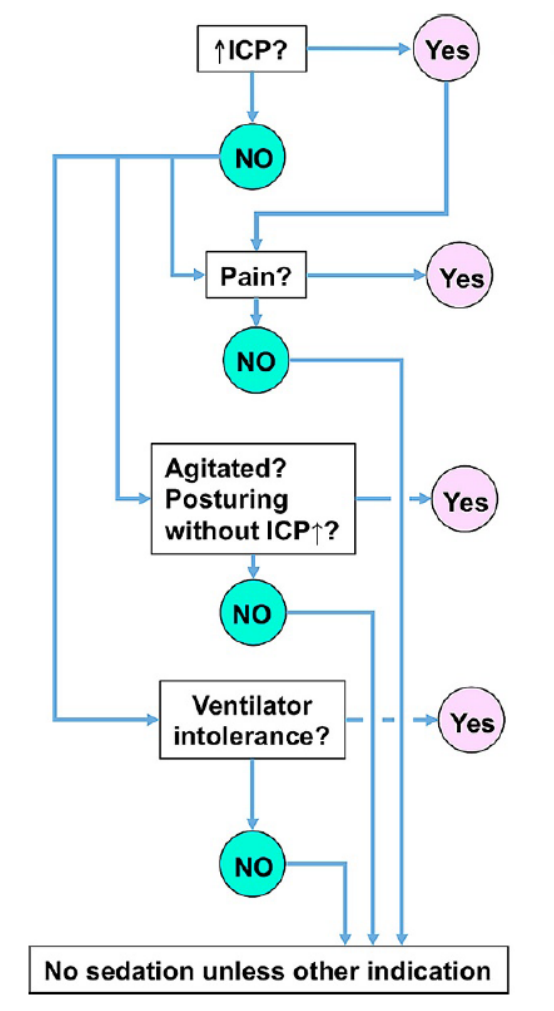

Monitor ICP, sedate to ICP/CMRO 2 targets ( \pm opioids)

Consider NMBs, keep propofol dose $<4 \mathrm{mg} / \mathrm{Kg} / \mathrm{h}$

(less in older and hypothermic patients) to reduce risk of Propofol Infusion Syndrome (PRIS)

Use/add/increase opioids - cautious with long-term remifentanil

Anxiolytics, benzodiazepines, alpha-2 agonists, haloperidol, olanzepine

\begin{tabular}{|c|c|}
\hline Opioids & $\begin{array}{l}\text { Investigational/novel approaches: } \\
\text { - Regimes based on alpha-2 agonists } \\
\text { - Volatile anaesthetics (not in } \uparrow \text { ICP) } \\
\text { - Xenon (not in } \uparrow \text { ICP) } \\
\text { - Etomidate + steroid cover } \\
\text { - Ketamine (Spreading Depression?) } \\
\text { Consider } \\
\text { Possible neurotoxicity of major } \\
\text { tranquilisers }\end{array}$ \\
\hline
\end{tabular}

Figure 9: A suggested scheme for optimal sedation in patients with traumatic brain injury. ICP, intracranial pressure; CMRO2, cerebral metabolic rate of oxygen; NMBs, neuromuscular blocking drugs.

et al., 2012; Alali et al., 2014). However, secondary brain injury from raised ICP or transient alterations in gas exchange during the tracheostomy must be carefully avoided.

\subsubsection{Sedation}

Sedation is often used in the acute phase of severe TBI. This is particularly the case in intubated patients in whom sedation improves tolerance of endotracheal intubation, promotes compliance with mechanical ventilation, and avoids ICP rises associated with coughing. In addition, sedative agents can intrinsically reduce ICP by reducing cerebral metabolic rate; a combination of hypnotic and opioid infusions has the additional benefit of suppressing cough and gag reflexes, and controlling pain, which is helpful for ICP control (Oddo et al., 2016). A suggested algorithm for rational use of sedatives is shown in Figure 9. The first-line sedative agent is typically propofol or a benzodiazepine, each of which has advantages and disadvantages. Propofol is more expensive, and tends to cause more hypotension. Though formal comparisons suggest that ICP control is similar with both agents overall (Sanchez-Izquierdo-Riera et al., 1998), midazolam may be less effective at controlling refractory intracranial hypertension, and tachyphylaxis to the drug may require increasing doses, with resulting accumulation of metabolites and delayed emergence from sedation (Shafer, 1998). However, despite this better control of intracranial hypertension, the use of high doses of propofol $(>4-5 \mathrm{mg} / \mathrm{kg} / \mathrm{h})$ for prolonged periods runs the risk of propofol infusion syndrome (PRIS) (Cremer et al., 2001). Accumulating evidence suggests that the profile of PRIS may be changing, and that the syndrome may be observed at lower doses in older patients (Krajcova et al., 2015), presumably due to slower elimination - a concern that may also apply to patients who are hypothermic (Dengler et al., 2015). Alternative sedative agents include ketamine, which may have particular benefits in reducing spreading depolarization (Hertle et al., 2012b), and dexmedetomidine, which may produce a better sedation profile, but at the risk of greater hypotension (Pajoumand et al., 2016).

A range of opioids has been used to supplement sedation in this setting, but recent interest has focused on remifentanil, the metabolism of which is context insensitive, and which may allow rapid emergence from sedation for neurological assessment (Karabinis et al., 2004). However, the agent is not appropriate for prolonged sedation during periods of intracranial hypertension, when the stability afforded by long-acting opioids may be beneficial. Agitation is common during the period of emergence from coma, and is commonly treated with butyrophenones, benzodiazepines, clonidine, or dexmedetomidine. There is continuing concern about the longterm effects of these agents, possibly through inhibition of plasticity (see later). While their use is unavoidable in many patients, attempts should be made to reduce their use if possible. 


\subsubsection{ICP and CPP targets}

ICP monitoring allows intracranial compliance and CPP to be targeted. It is typical for intracranial hypertension to rise over the first several days, plateau, and then slowly resolve. High levels of ICP are associated with mortality (Balestreri et al., 2006), and even brief (>5 minutes) episodes of intracranial hypertension are associated with worse outcome (Stein et al., 2011). Consequently, intracranial hypertension is a prominent target in TBI guidelines. However, there continues to be lack of certainty about what thresholds of ICP justify therapies that have intrinsic toxicities (see later), and the definition of the critical "dose" of intracranial hypertension remains an important, but elusive, goal (Chesnut et al., 2015).

Similarly, the choice of CPP targets in TBI is not based on high-quality evidence. The original Brain Trauma Foundation (BTF) guidelines (Brain Trauma Foundation, American Association of Neurological Surgeons, The Joint Section on Neurotrauma and Critical Care, 2000) recognized the limited evidence in this area, but suggested a CPP threshold of $70 \mathrm{mmHg}$ as a treatment option. However, there was recognition of alternative models of CPP management, such as the Lund protocol (Grande, 2006). A landmark paper by Robertson and colleagues (1999) suggested that the cerebral haemodynamic benefits of CPP elevation were substantially offset by cardiopulmonary complications associated with fluid loading and vasoactive drugs used for rigorous CPP maintenance. These findings led to a revision of CPP targets in a subsequent version of the BTF guidelines (Brain Trauma Foundation, American Association of Neurological Surgeons, Congress of Neurological Surgeons, 2007b), which advised against aggressive interventions to maintain $\mathrm{CPP}$ above $70 \mathrm{mmHg}$. More recent discussions recognize that optimal CPP (and ICP) targets may vary between patients, and at different stages of the disease trajectory in the same patient (Hutchinson et al., 2013). Multimodality monitoring may allow context-dependent refinement of physiological targets (Sorrentino et al., 2012; Lazaridis et al., 2014).

\subsubsection{Blood glucose targets}

Admission hyperglycaemia (blood glucose $>180 \mathrm{mg} / \mathrm{dL}$ ) has been repeatedly associated with worse outcomes in TBI (Van Beek et al., 2007), but tight glycaemic control may trigger critically low brain glucose levels (Oddo et al., 2008; Meierhans et al., 2010), especially in injured regions (Magnoni et al., 2012), as well as cerebral energy crisis (Oddo et al., 2008), increased risk of spreading depression (Parkin et al., 2005), and poor outcome (Vespa et al., 2003). Concerns have been further heightened by an increasing recognition that tight glycaemic control in TBI is associated with increased risk of hypoglycaemia (Finfer et al., 2015), and current advice focuses on the avoidance of hyperglycaemia without aiming for tight glycemic control (Kramer et al., 2012). It is worth reflecting, however, that intensive glycaemic control that avoided hypoglycaemia was associated (in a single-centre study) with improved outcomes (Van den Berghe et al., 2005), and that safer approaches to tight glycaemic control might allow the adoption of time-varying individualized blood glucose targets (Meier et al., 2008), perhaps guided by microdialysis monitoring of brain glucose levels.

\subsubsection{Temperature management}

Decisions about temperature management in TBI address three main issues: the use of therapeutic hypothermia as a universal neuroprotective intervention, use of hypothermia as a treatment for intracranial hypertension, and the avoidance of hyperthermia (fever control). Despite substantial supportive evidence from case series and single-centre trials, multicentre trials (Clifton et al., 2001, 2011) failed to show benefit of universal cooling to $32-34^{\circ} \mathrm{C}$, and a recent systematic review (Saxena et al., 2014) could find no evidence to support less intensive hypothermia in TBI. Therapeutic hypothermia is known to effectively reduce ICP, but the recent Eurotherm3235 Trial (Andrews et al., 2015) showed no benefit from titrated cooling to maintain ICP less than $20 \mathrm{mmHg}$. Recent interest has focused on the use of targeted temperature management to avoid fever in TBI, and two recent studies suggest that this strategy may be superior to induced hypothermia (Maekawa et al., 2015; Hifumi et al., 2016). Current practice, based on limited evidence, focuses on treating significant elevations in temperature (above a threshold of $38.0-38.5^{\circ} \mathrm{C}$ ), and the continued use of hypothermia for ICP control, but with higher ICP thresholds (typically 25-30 mmHg; O'Leary et al., 2016).

\subsubsection{Seizure prophylaxis}

Guidelines recommend the use of 7 days of antiepileptic drug (AED) therapy to reduce early seizures after TBI (Chang and Lowenstein, 2003; Brain Trauma Foundation, American Association of Neurological Surgeons, Congress of Neurological Surgeons, 2007d) in patients with risk factors (GCS score <10; cortical contusion; depressed skull fracture, SDH; EDH; intracerebral haematoma; penetrating head wound). There is no role for using early AED therapy to prevent late posttraumatic seizures. Levetiracetam may have a better safety profile compared to phenytoin, which has been the traditional AED in use in this context (Xu et al., 2016). The detection and treatment of NCS (see earlier section) may be facilitated by continuous EEG monitoring. 


\subsubsection{Osmotic therapy}

Infusions of hyperosmotic agents are effective in controlling cerebral edema. Hypertonic saline is effective (Lazaridis et al., 2013), and may be preferred over mannitol, as it expands intravascular volume, and (unlike mannitol) is not associated with a subsequent diuresis which may lead to hypovolaemia and hypotension. These attributes may explain why recent meta-analyses suggest that hypertonic saline may be more effective in ICP management (Kamel et al., 2011; Li et al., 2015). There appears to be no benefit from using hyperosmotic solutions prophylactically to prevent ICP elevations after TBI (Ryu et al., 2013).

\subsubsection{Routine ICU interventions}

Current guidelines recommend the early initiation of enteral nutrition, aiming to achieve full caloric supplementation by 7 days post-TBI (Brain Trauma Foundation, American Association of Neurological Surgeons, Congress of Neurological Surgeons, 2007c). Stress ulcer prophylaxiswithH2-receptor antagonists or a proton pump inhibitor is commonly used, at least until full enteral feeding is established. Coagulopathy is common in TBI, as is the incidence of venous thromboembolic disease; both issues are discussed in a later section. Electrolyte abnormalities are common in TBI - osmotic diuretics and cold diuresis may result in electrolyte loss. It is common to encounter both hypernatraemia (due to hyperosmotic therapy, relative free-water restriction, or diabetes insipidus) and hyponatraemia (due to the syndrome of inappropriate antidiuretic hormone secretion, cerebral salt wasting, or inappropriate use of hypotonic fluids). Therapy in the acute phase should aim to correct these abnormalities, while avoiding any hyponatraemia (which may increase cerebral edema) or hypovolaemia (which may make CPP targets difficult to achieve).

\subsection{9 "Second-line" and rescue therapies}

A number of strategies are available which, although potentially harmful, may be effective in controlling otherwise refractory intracranial hypertension. Brief periods of hyperventilation can be effective for reducing ICP and the risks of vasoconstriction and ischaemia may be mitigated by simultaneously monitoring $P b t \mathrm{O}_{2}$ or jugular venous oxygen saturation. However this procedure is only transiently effective until CSF chemistry adjusts and is at best suitable for use only as an emergency temporizing measure. The routine early use of aggressive cooling (core temperatures $32-34^{\circ} \mathrm{C}$ ) is associated with worse outcome (Andrews et al., 2015). Hypothermia is associated with cardiovascular instability, coagulopathy, immunosuppression, and electrolyte shifts, which are highly undesirable. However, as a rescue therapy, it is nevertheless effective in reducing ICP and should be considered. Where hypothermia is employed, rewarming must be very slow.

Similarly, whilst early decompressive craniectomy for relatively moderate intracranial hypertension has been shown not to improve outcome after TBI (Cooper et al., 2011), it is effective in controlling otherwise refractory intracranial hypertension. The Randomized Evaluation of Surgery with Craniectomy forUncontrollable Elevation of Intra-Cranial Pressure (RESCUEicp) trial has studied decompressive craniectomy as a rescue therapy for persistent ICP $>25 \mathrm{mmHg}$, and can result in increased survival at 6 months, with improved functional outcome at 12 months, but at the expense of increased numbers of survivors with severe disability (Hutchinson et al., 2016).

A final rescue strategy that may be employed for medical management of refractory ICP elevation is metabolic suppression through deep sedation to the point of a near isoelectric EEG. This may be achieved using barbiturates, which are known to suppress metabolism, reduce excitotoxicity, and inhibit lipid peroxidation. Again, prophylactic or early use in preference to osmotherapy is known to be ineffective and potentially harmful. At the high doses required, barbiturates are associated with haemodynamic instability and hypotension, which offset ICP-lowering effects (Roberts and Sydenham, 2012), as well as respiratory complications, hypokalaemia, and hepatic and renal impairment. Their long elimination times are also undesirable. Again, however, barbiturates are effective in lowering ICP (Majdan et al., 2013) and should nevertheless be considered as a rescue therapy.

\subsection{ICP and CPP management protocols}

The rational use of the many available treatment options for ICP and CPP control is facilitated by the use of protocols. The algorithm in use in Cambridge is shown as an example (Fig. 10). Although other centres may use protocols that differ in detail, the broad principles remain the same, with establishment of both systemic and brain-specific monitoring. Consideration should be given to clinically significant lesions that may be evacuated (e.g., subdural or extradural haematomas causing mass effect). Any change in intracranial physiology or increasing difficulty in controlling ICP should trigger a search for new or evolving pathology that may be amenable to surgical intervention. Drainage of CSF via a ventriculostomy should ideally be an early intervention for intracranial hypertension, but must, in any case, be contemplated before escalation of medical therapies or before surgical decompression. 


\section{Traumatic Brain Injury ICP/CPP Algorithm}

Patients with traumatic brain injury (TBI) admitted to the NCCU are managed according to this protocol. Each step of
the protocol must be preceded by thorough checking of the position and accuracy of all intracranial monitoring.
Surgical referral for evacuation of significant space occupying lesion(s) (SOL) is mandatory before escalating
medical treatment. Consider EVD insertion before escalating medical treatment.
All patients managed according to this protocol must have the following within 4 hours of admission to NCCU:
1) invasive arterial (transducer at the tragus) and central venous catheter
2) ICP monitoring
3) Cerebral microdialysis catheter and $\mathrm{PbO} 2$ probe
4) ICM+
Initial target of CPP of $65 \mathrm{mmHg}(\mathrm{CPP}>55 \mathrm{mmHg}$ may be acceptable). Autoregulation parameters and brain
biochemistry are used to individualise targets.

\begin{tabular}{|c|c|}
\hline 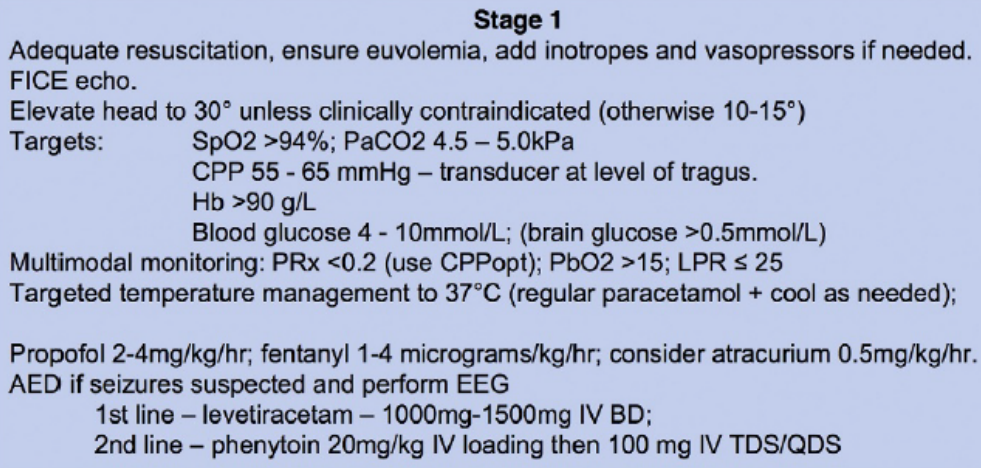 & $\begin{array}{l}\text { If ICP }>\mathbf{2 0} \mathbf{m m H g} \\
\text { escalate to STAGE } \mathbf{2} \text {, } \\
\text { consider rescan and } \\
\text { evacuation of SOL }\end{array}$ \\
\hline $\begin{array}{l}\text { Drain CSF via EVD at } 5-10 \mathrm{cmH}_{2} \mathrm{O} \\
\text { Using CVC, } 5 \% \mathrm{NaCl} 2 \mathrm{ml} / \mathrm{kg} \mathrm{IV}-\text { repeat until plasma } \mathrm{Na}+>160 \mathrm{mmol} / \mathrm{l} \\
\text { or plasma osmolality } \approx 320 \mathrm{mOsm} / \mathrm{kg} \text { ) } \\
\text { Induce mild hypothermia }-\approx 35^{\circ} \mathrm{C} \text {; daily lipids, ECG and } \mathrm{CK} \text { if still on propofol }\end{array}$ & $\begin{array}{l}\text { If ICP }>20 \mathrm{mmHg} \\
\text { escalate to STAGE } 3 \text {, } \\
\text { consider rescan and } \\
\text { evacuation of SOL }\end{array}$ \\
\hline $\begin{array}{l}\text { Trial of CPP }>70 \mathrm{mmHg} \\
\text { Advanced haemodynamic monitoring }- \text { further optimise cardiovascular function } \\
\text { AEDs if not already initiated and daily lipids, ECG and } \mathrm{CK} \text { if still on propofol }\end{array}$ & $\begin{array}{l}\text { If ICP }>25 \mathrm{mmHg} \\
\text { escalate to STAGE } 4 \text {, } \\
\text { consider rescan and } \\
\text { evacuation of SOL }\end{array}$ \\
\hline $\begin{array}{l}\text { Stage } 4-\text { NCCU Consultant approval only } \\
\text { Moderate hypothermia to } 32-34^{\circ} \mathrm{C} \text {. } \\
\text { Change propofol to midazolam } 1-20 \mathrm{mg} / \mathrm{hr}( \pm 2 \mathrm{mg} / \mathrm{kg} / \mathrm{hr} \text { propofol }) \\
\text { - daily lipids, ECG and CK if still on propofol }\end{array}$ & $\begin{array}{l}\text { If ICP }>25 \mathrm{mmHg} \\
\text { escalate to STAGE } 4 \text {, } \\
\text { consider rescan and } \\
\text { evacuation of SOL }\end{array}$ \\
\hline $\begin{array}{l}\text { Stage } 5-\mathrm{NCCU} \text { Consultant approval only } \\
\text { Add IV anaesthetic (e.g. propofol } 1 \mathrm{mg} / \mathrm{kg} \text { IV stat) - maintain CPP. } \\
\text { If ICP and CPP improve, start thiopental: } 250 \mathrm{mg} \text { boluses up to } 3-5 \mathrm{~g} \text {, then } 3-8 \mathrm{mg} / \mathrm{kg} / \mathrm{hr} \\
\text { Burst suppression ratio } \gg>50 \%\end{array}$ & $\begin{array}{l}\text { Consider } \\
\text { decompressive } \\
\text { craniectomy } \\
\text { (mandatory NCCU } \\
\text { consultant } \\
\text { discussion) }\end{array}$ \\
\hline
\end{tabular}

Version 19

June 2016

Figure 10: Cambridge traumatic brain injury (TBI) intracranial pressure (ICP)/cerebral perfusion pressure (CPP) management algorithm. NCCU, neurosciences critical care unit; EVD, external ventricular drain; FICE, focused intensive care echo; PRx, pressure-reactivity index; CPPopt, optimal range for autoregulation; LPR, lactate:pyruvate ratio; EEG, electroencephalogram; CSF, cerebrospinal fluid; CVC, central venous catheter; ECG, electrocardiogram; CK, creatine kinase; AEDs, antiepileptic drugs. 


\section{Clinical trials and guidelines}

A clinically effective pharmacological neuroprotective intervention continues to elude us (Janowitz and Menon, 2010; Menon and Maas, 2015; Bragge et al., 2016). The last few years have seen further negative neuroprotection trials of erythropoietin and hypothermia, and shown no benefit from higher transfusion thresholds in TBI. Given the limited class I evidence available, clinical protocols and guidelines have been largely based on expert consensus, both for monitoring (Le Roux et al., 2014) and for treatment. The 2007 BTF guidelines for in-hospital management of TBI provided a pragmatic synthesis of the (often relatively poor-quality) available evidence on TBI management (Brain Trauma Foundation, American Association of Neurological Surgeons, Congress of Neurological Surgeons, 2007a).

These guidelines probably provided the most commonly used evidence base for critical care management of TBI. A more recent revision (Brain Trauma Foundation, American Association of Neurological Surgeons, Congress of Neurological Surgeons, 2016) provides conclusions more stringently based on high quality evidence, with a reduced number of recommendations, which include a treatment threshold of $22 \mathrm{mmHg}$ for ICP, and a CPP target of between 60 and $70 \mathrm{mmHg}$, with choice of target depending on individual autoregulatory status. This revision highlights the paucity of high-quality evidence to guide therapy. However, it provides little guidance on what might be seen as best practice, even in the absence of high quality evidence.

Retrospective analyses (Patel et al., 2005; Brown et al., 2010; Tepas et al., 2013) suggest that mortality, functional outcome, and cost-effectiveness are improved by transferring TBI patients to specialist trauma or neurosurgical centres, and possibly by transfer to high-volume centres (seeing greater than 40 cases of severe TBI per quarter: Tepas et al., 2013). In addition, many studies suggest that intensive protocol-driven therapy (typically based onBTF guidelines, and including ICP monitoring) results in lower mortality and better outcomes (Bulger et al., 2002; Elf et al., 2002; Patel et al., 2002; Fakhry et al., 2004; Fuller et al., 2011;Alali et al., 2013). In addition, a large prospective study of TBI patients requiring intensive care, which corrected for key known covariates, showed that transfer to specialist centres was cost-effective, even for patients who did not require an acute operative neurosurgical intervention (Harrison et al., 2013). While these data drive current practice in many countries, these analyses cannot account for unmeasured confounders, and evidence of such benefit is inconsistent: at least one study (Cremer et al., 2005) and two recent meta-analyses (Su et al., 2014; Yuan et al., 2015) suggest no overall benefit from aggressive, ICP-guided management. Indeed, the BESTTRIP trial (which represents the only class I evidence in this context) suggests that clinical care based on imaging and serial clinical examination, at least in low- and middle-income countries, is not inferior to a strategy based on ICP-guided management (Chesnut et al., 2012). The case has been made for repeating this study in centres from high-income countries (Chesnut et al., 2015). New approaches have emerged for optimizing this translational process. At one end of this pathway there has been a drive to use experimental medicine approaches in the clinical laboratory of the neurointensive care unit (Janowitz and Menon, 2010), so as to optimize our understanding of pathophysiology, document its modulation by both existing and novel interventions, and find ways to stratify patients into groups that are more likely to respond to a given intervention. At the other end of the translational pathway there has been increasing interest in using precision medicine and comparative effectiveness research (Maas et al., 2012) to advance research and clinical care in TBI - these themes are the focus of a large international initiative (http://intbir.nih.gov/).

\section{Complex clinical decisions}

\subsection{Haemostatic abnormalities after TBI}

TBI is associated with both haemostatic deficits and hypercoagulopathy (Laroche et al., 2012; Maegele, 2013), with up to $60 \%$ of patients showing abnormal values in severe TBI (Hoyt, 2004). Risk factors include injury severity, age, and prehospital hypotension (Wafaisade et al., 2010a, b). Many patients have delayed worsening of haemostasis (Lustenberger et al., 2010; Greuters et al., 2011). Admission coagulopathy is associated with a 10fold increase in mortality and a 30-fold increase in poor outcome in TBI (Harhangi et al., 2008; Wafaisade et al., 2010a; Greuters et al., 2011). Platelet count below 175 000/mL increases the risk of ICH progression, and counts less than 100 000/mL independently predict mortality. Antiplatelet agents or anticoagulants modulate outcome (Batchelor and Grayson, 2012a, b; Grandhi et al., 2015). Preinjury warfarin (Batchelor and Grayson, 2012a) increases the risk of poor outcome, but the reported impact of antiplatelet agents is inconsistent (Batchelor and Grayson, 2013; Fabbri et al., 2013; Joseph et al., 2014). In addition, selective serotonin reuptake inhibitors may have significant effects on haemostasis (Hackam and Mrkobrada, 2012), but their impact on TBI course and outcome is poorly investigated. Finally, the newer target-specific oral anticoagulants (also termed newer oral anticoagulants) confer new (and as yet poorly quantified) risks to patients with TBI (Miller et al., 2014). Much of the literature on haemostatic abnormalities in TBI has focused on conventional laboratory assays, but these may correlate poorly with bleeding risk and need for haemostatic correction. "Global" haemostatic tests, such as viscoelastic assays (TEG and ROTEM), and thrombin generation tests, may provide more integrated 
information regarding haemostatic potential, dynamic haemostasis, and clot stability, and may hence be more clinically relevant (Schochl et al., 2011). Recent consensus recommendations address viscoelastic thresholds for treatment in trauma (Inaba et al., 2015) (Fig. 2), and, if validated in TBI, could contribute to precision medicine approaches to managing coagulopathy in TBI.

Current treatment strategies for managing haemostatic defects in TBI follow those for general trauma, except for avoiding permissive hypotension, and targeting higher platelet counts $(>100109 / \mathrm{L})$ in the acute phase. The use of early empiric use of fresh frozen plasma and platelets has not been shown to be beneficial in TBI (Etemadrezaie et al., 2007; Anglin et al., 2013). While blood components continue to be commonly used to correct coagulation abnormalities, there is increasing interest in the use of factor concentrates (Narayan et al., 2008; Spahn et al., 2013; Yanamadala et al., 2014) and haemostatic drugs such as desmopressin and tranexamic acid (TXA). A subgroup analysis in the CRASH-2 trial suggested that TXA may reduce haemorrhage growth (Perel et al., 2012). The restriction of benefit to administration of TXA within 3 hours after injury in the overall trauma population in CRASH 2 (CRASH-2 collaborators et al., 2011) has not been as yet confirmed or refuted in TBI, but may be resolved by the currently recruiting CRASH-3 study (Dewan et al., 2012).

\subsection{When to start thromboprophylaxis}

The association between trauma and venous thromboembolism is well established. Pharmacological thromboprophylaxis appears to be safe among TBI patients with stabilized or improved haemorrhagic patterns (Shen et al., 2015). However, additional evidence is needed regarding effectiveness of the intervention, and better clarification of preferred agents, dose, and timing. With no evidence of intracranial bleeding, many clinicians would consider starting low-molecular-weight heparin prophylaxis within 48-72 hours of injury, but this would be delayed by up to 2 weeks with intracranial bleeding (Jamjoom and Jamjoom, 2013). Pharmacological thromboprophylaxis is associated with a 13-fold increase in odds of further haemorrhage progression for those patients whose follow-up cranial computed tomography within 1 day of admission showed ICH progression (Levy et al., 2010). Stratification scores for the identification of TBI patients with low, moderate, or high risk for spontaneous cerebral bleeding may help to allow early thromboprophylaxis while maintaining a good risk-benefit ratio (Schaible and Thal, 2013).

\subsection{The elderly patient}

Older individuals in high-income countries are at high risk of TBI (Faul et al., 2010; EuroSafe, 2013; Feigin et al., 2013). Limited data from low- and middle-income countries (Hyder et al., 2007) do not show this, but demographic projections and urbanization suggest that TBI in the elderly is likely to become a growing global problem. Overall, the median age of patients likely to be cared for in critical care units and included in observational studies has doubled since the 1980s (Fig. 1.4), and the percentage of patients 50 years of age increased threefold (Roozenbeek et al., 2013).

While this substantial rise in the incidence of TBI in older patients is partly attributable to an aging population, it is also due to the increased health and mobility of older patients, and increased case ascertainment due to the commoner use of protocol-driven CT imaging. These patients have a high need for hospitalization $(50 \%)$ and a high mortality (with injury-related mortality doubling in EU statistics from 1990 to 2010 , from $38 \%$ in 1990 to $49 \%$ in 2010; EuroSafe, 2013).

Some of this increased morbidity may be due to reduced physiological reserve and frailty, with cardiovascular and other comorbidities impacting outcome in this age group. In addition, the therapies used for common comorbidities, such as anticoagulant and antiplatelet therapy, increase the risk of intracranial haemorrhage following TBI. Pre-existing neurodegenerative and cerebrovascular disease may also limit cognitive reserve and limit the scope for recovery. These differences have prompted some reassessment of TBI severity in older subjects (Kehoe et al., 2015) and lead to lower thresholds for referral to specialist care (Caterino et al., 2011). However, the broader picture is more worrisome. Patients over the age of 65 years are rarely recruited to RCTs. Further, there is substantial nihilism in the management of older patients with TBI, who experience less aggressive therapy, delayed CT imaging, lower likelihood of transfer to specialist neurosurgical facilities, and care by more junior medical staff (Kirkman et al., 2013). Treatment limiting decisions may be more frequently justified in this group, but initial active therapy, coupled with reassessment of progress and response to therapy, provides some opportunities for rational stratification. In carefully selected subsets, aggressive therapy, including decompressive craniectomy, may deliver good outcomes (De Bonis et al., 2011) in between 39\% and 50\% of older patients (Stocchetti et al., 2012) and better long-term life satisfaction after severe TBI (Anke et al., 2015).

\subsection{Monitoring the nonassessable patient}

Where patients present with clear signs of a space occupying lesion, or other evidence of raised ICP on neuroimaging, most centres would seek to place an ICP monitor to guide sedation and management of cerebral edema. 
When the CT is unimpressive or borderline in a patient who has been sedated and intubated prior to imaging, many centres would seek to hold sedative drugs for a brief period to assess neurological status, and proceed to sedation withdrawal and extubation if the patient was neurologically appropriate. However, this strategy may not be possible in patients in whom significant extracranial injury or physiological instability precludes sedation reduction. In such situations, the options are to either place an ICP monitor, or be guided by serial imaging. Both strategies are used, and the decision in any individual case needs to balance the small but definite risks of ICP placement against the possibility that near-normal imaging may coexist with intracranial hypertension, and certainly cannot detect episodic ICP elevations.

\subsection{Balancing second-tier therapies}

The evidence base for clinical practice in TBI is limited in general. This paucity of evidence becomes particularly acute in the context of the 10-20\% of patients with intracranial hypertension refractory to first-line therapies (Stocchetti et al., 2008), since commonly used second tier therapies (hypothermia, decompressive craniectomy, and metabolic suppression) are all associated with significant side-effects. Decision making in this context is further complicated by the results of the Decompressive Craniectomy in Diffuse Traumatic Brain Injury (DECRA) (Cooper et al., 2011) and Eurotherm3235 trials (Andrews et al., 2015), which suggest lack of benefit or even harm from the use of decompressive craniectomy and harm from induced hypothermia. However, it is important to note that both trials tested the two therapies early in the management algorithm for intracranial hypertension, rather than for refractory intracranial hypertension unresponsive to standard therapies. This is a critical issue, since the calculus balancing risk and benefit may be very different in this context (O'Leary et al., 2016): while the threshold for harm or mortality is not clear, there is little doubt that marked and sustained ICP elevation (well above the normal treatment threshold of $20 \mathrm{mmHg}$ ) is a strong driver of mortality (Balestreri et al., 2006). A recently completed study of decompressive craniectomy as a rescue therapy for refractory intracranial hypertension, however, suggests a mortality benefit at six months, which translates into improved functional outcome (measured as independent survival at home or better) by 12 months. However this was also associated with an increase in severely disabled survivors (Hutchinson et al. 2016). However, there is no currently active trial that examines the use of induced hypothermia in a similar context. Until such data become available, it is difficult to provide recommendations on using or withholding any one of these three therapies in patients in whom refractory intracranial hypertension represents a significant hazard to life.

\subsection{When to transfuse}

Adequate haemoglobin concentration is essential for oxygen delivery. However, transfusion is associated with a number of risks in the critically ill, including increased rates of infection, thromboembolism, and death. Whilst a restrictive transfusion threshold of $7 \mathrm{~g} / \mathrm{dL}$ is widely regarded as safe in most critically ill patients (Hebert et al., 1999), including those after cardiac surgery (Hajjar et al., 2010), there have been concerns that this level may be insufficient for those patients with TBI where oxygen delivery may be critical.

Outcome differences have not been demonstrated between restrictive and liberal transfusion strategies after TBI in randomized controlled trials (McIntyre et al., 2006; Robertson et al., 2014) and liberal transfusion has been associated with increased incidence of adverse events (Robertson et al., 2014). Observational studies have also signalled that transfusion may be associated with worse long-term outcome (Warner et al., 2010; Elterman et al., 2013; Leal-Noval et al., 2016). There is also some evidence to suggest that higher transfusion thresholds of $10 \mathrm{~g} / \mathrm{dL}$ may predispose to progression or development of intracerebral haematomas (Vedantam et al., 2016), implicating a mechanism involving microvascular damage from transfused blood.

At the same time, higher haemoglobin concentrations are associated with improved cardiovascular stability. Furthermore, there is evidence for a detrimental influence of anaemia on cerebral oxygenation. Transfusion acutely improves brain tissue oxygenation (Smith et al., 2005; Zygun et al., 2009), although this does not have a measurable effect on cerebral metabolism (Zygun et al., 2009). Increased rates of brain tissue hypoxia have been detected with transfusion thresholds of $7 \mathrm{~g} / \mathrm{dL}$ compared to $10 \mathrm{~g} / \mathrm{dL}$ (Yamal et al., 2015), and this was associated with an increased risk of early death, but a reduced risk of late death. Given the lack of definitive evidence, a reasonable approach would be to individualize transfusion thresholds according to the prevailing physiology as measured by multimodality monitoring.

\subsection{Managing multiple trauma in the context of TBI}

TBI commonly coexists with extracranial trauma, particularly after high-energy mechanisms such as road traffic collisions or falls from height. Severe extracranial injury may have a significant impact on TBI.

There have been significant advances in trauma management over the last decade or so. There has been a trend towards permissive hypotension in the ultra-early phase of management, motivated by concerns regarding the development of coagulopathy (Morrison et al., 2011). However, this must be balanced against the known 
dangers of arterial hypotension in severe TBI and thus is probably not appropriate for most of these patients. At the same time there has been a move towards damage control surgery to control early haemorrhage. The use of early whole-body CT has been demonstrated to confer a survival benefit after major trauma (Huber-Wagner et al., 2009) and improvements in imaging technology have increased speed and availability to such an extent that even relatively unstable patients can be scanned. This is immensely helpful, not only for planning surgery, but also for identifying the extent of TBI before damage control and therefore personalizing physiological targets very early, hopefully limiting harm from unnecessarily aggressive resuscitation.

There is no good evidence to guide the timing of orthopedic interventions, and the expert view on timing for such surgery has been organized under the rubrics of early total care (early definitive fixation) (Bone et al., 1989), damage control orthopedics (which focuses on the stabilization of injuries, usually with external fixation (Pape et al., 2009)), and (most recently) early appropriate care (which allocates management strategies based on physiological stability, response to resuscitation, and other risk factors) (Vallier et al., 2013). While the last of these three strategies would seem to be most rational, in effect, the presence of moderate or severe TBI (Pape et al., 2009), especially with the need for cranial surgery (Vallier et al., 2013), places patients in a high-risk category, or excludes them from these schemes. Definitive management of fractured extremities is generally not an emergency. However, fractures are painful and may have a deleterious influence on ICP, as well as convey an increased risk of fat embolus, acute lung injury, and ongoing haemorrhage until the fracture is fixed. Conversely, the increased blood loss and haemodynamic instability associated with more definitive procedures may increase the risk of low CPP and/or high ICP. These decisions are best individualized, based on physiological stability, intracranial compliance, and logistic feasibility. Occasionally there may be a window of opportunity for fixation in the first few days postinjury, as intracranial compliance may be preserved before cerebral edema develops, while external fixation may be feasible in patients who are too unstable to undergo definitive fixation. Pelvic fractures can pose particular problems due to their propensity for bleeding, associated risk of venous thromboembolism, and restriction on patient positioning. Combined with early CT angiography, endovascular embolization of bleeding pelvic vessels has made minimally invasive haemorrhage control possible. At the same time, temporary inferior vena cava filters are increasingly used to prevent venous thromboembolism in patients with multiple injuries, but in whom prophylactic anticoagulation is not possible due to the nature of their TBI.

Spinal injuries often coexist with TBI, and a proportion of such cases also have spinal cord involvement. Like the brain, the spinal cord is also sensitive to secondary injury from a fall in perfusion pressure; hypotension must therefore be avoided, and there is some evidence to support maintenance of an elevated systemic arterial pressure to optimize cord perfusion (Vale et al., 1997; Hawryluk et al., 2015). Surgical decompression should ideally not be delayed (Fehlings et al., 2012), but TBI or other injuries may make this difficult. Where possible, early fixation of concurrent spinal injuries is helpful in limiting pulmonary complications and may improve outcome (O'Boynick et al., 2014).

Pulmonary injuries pose a significant challenge in the presence of TBI. Acute respiratory distress syndrome occurs in over $20 \%$ of severe TBI patients (Aisiku et al., 2016), as a result of direct pulmonary trauma, aspiration pneumonitis or later infection, or as a complication of resuscitation. Although this patient group has been little studied, the mortality benefit of low-tidal-volume mechanical ventilation with permissive hypercapnia to avoid volutrauma/barotrauma is generally accepted (The Acute Respiratory Distress Syndrome Network, 2000), but may be difficult to achieve in patients in whom intracranial compliance is poor and hypercapnia leads to substantial rises in ICP. The use of fluids and vasoactive agents for CPP management along with secondtier therapies such as hypothermia and barbiturates may further aggravate respiratory failure, particularly in patients with myocardial injury.

The need to avoid secondary neurologic injury due to hypoxaemia demands meticulous intensive care management. Extracorporeal membrane oxygenation has been successfully used in TBI patients, but anticoagulation risks haematoma expansion/haemorrhage. Less invasive technologies for extracorporeal carbon dioxide elimination have advanced significantly in recent years and may also have a role in limiting the impact of mechanical ventilation in such complex patients (Munoz-Bendix et al., 2015).

\section{Neurorehabilitation}

Debate exists regarding the optimal timing for rehabilitation interventions. Some centres advocate early inhospital initiation (Andelic et al., 2014), but most rehabilitation centres will only accept patients when they are "trainable" (i.e., after return of consciousness and once they are out of posttraumatic amnesia). There is a strong case to be made for embedding the rehabilitation ethos into acute care of TBI, from the point of admission. During the acute TBI phase, interventions need to focus on maximizing preservation of neurological function, avoiding secondary complications, and maintaining musculoskeletal function to provide a basis for subsequent rehabilitation. The more direct rehabilitation-related interventions become relevant as patients begin to improve.Key interventions in this context address ensuring adequate delivery of nutrition (usually enterally), 
limiting the duration of neuromuscular blockade to avoid muscle wasting, timely treatment of infections, and minimization of sedatives and other medication (such as first-generation AEDs) that have been associated with worse rehabilitation outcomes. The last of these issues may demand careful clinical judgement, since drugs may be needed to control agitation and ensure patient safety. Agitation is common during the process of recovery from TBI, may adversely affect engagement with rehabilitation, andmay be associated with worse outcomes (Bogner et al., 2001; Lequerica et al., 2007). Many agents, including benzodiazepines, butyrophenones, atypical antipsychotics, beta-blockers, and antiepileptic agents have been used to treat this condition, but none is uniformly successful (Fugate et al., 1997; Levy et al., 2005; Fleminger et al., 2006). Experimental data suggest that some of these agents may impede recovery (Kline et al., 2008) and rehabilitative learning (Hoffman et al., 2008) after TBI. While these data have not been convincingly replicated in humans, and use of these agents is often unavoidable in behavioural emergencies, a careful analysis of the risk-benefit ratio is warranted in each patient.

Prompt attention to extracranial injuries can facilitate mobilization and physiotherapy. Physiotherapy, first with passive movements and later with active exercises, may help minimize spasticity and fixed joint deformities. Particularly resistant spasticity may benefit from local injections of botulinum toxin. In patients with severe TBI and a compromised level of consciousness or airway incompetence, or in those with severe extracranial injuries, early tracheostomy may accelerate liberation from ventilator support. Paroxysmal sympathetic hyperactivity is not uncommon in severe TBI, especially in patients with extensive TAI, and the careful selection and titration of medication (including, for example, beta-blockers, clonidine, gabapentin) aimed at minimizing sympathetic storms may allow rapid reduction of sedative medication. Injections of botulinum toxin into the parotid glands may be beneficial in patients in whom hypersalivation is a particular problem. An additional issue of direct relevance to intensivists is the use of drugs to accelerate emergence from coma (Mura et al., 2014); the only well-conducted positive randomized clinical trial involves administration of amantadine (Giacino et al., 2012).Notwithstanding use of such agents, it is important to emphasize that early targeted rehabilitative therapies may be important in achieving the best possible outcome in this setting (Seel et al., 2013).

TBI may begin as an acute condition, but eventually becomes a chronic disease, with an ongoing burden of excess mortality persisting decades after the initial injury, and persistent disability that continues to affect quality of life. Besides physical disability, TBI survivors suffer from pervasive cognitive deficits (particularly in mental energy, memory, attention, and learning), mental health sequelae (including depression and posttraumatic stress disorder), and impaired self-regulatory behaviour (increased impulsivity, poor decision making, and impulsive-aggressive behaviour). TBI is also an important risk factor for late posttraumatic epilepsy, with a reported incidence of $0.2-14 \%$ for nonpenetrating TBI (Ding et al., 2016) and a substantially increased risk following penetrating TBI (odds ratio 18.77, confidence interval 9.21-38.23) (Pugh et al., 2015). These problems hamper community and vocational integration and quality of life (Andelic et al., 2009; Corrigan et al., 2014), and may trigger institutional placement. TBI survivors may also suffer sleep disorders, neuroendocrine dysregulation, bowel and bladder incontinence, and late (sometimes progressive) abnormalities in metabolic regulation.

TBI may also be a progressive disease. A 13-year longitudinal study (McMillan et al., 2011) showed high rates of disability (50\%) and death during follow-up (40\%), with substantial change in the level of disability and dependency during follow-up, with about $50 \%$ of survivors experiencing reclassification on the Glasgow Outcome Scale - Extended (GOSE). Half of these involved an improvement in functional level, but the rest worsened between 7 and 14 years post-TBI. The GOSE initially increases and peaks approximately 10 years postinjury, and then decreases (Pretz and Dams-O'Connor, 2013). There is also now a clear recognition that TBI is an important risk factor for late neurodegeneration (Shively et al., 2012; DeKosky et al., 2013; Smith et al., 2013), underpinned by a polypathology (Washington et al., 2016) that involves deposition of protein aggregates (such as amyloid and hyperphosphorylated tau), and neuroinflammation. One major challenge for neurointensive care in the future may be the characterization of such late consequences of TBI, and their modulation by therapies that we deliver in the ICU.

\section{Outcome}

Given the burden of disability arising from TBI, it follows that simple estimates of mortality would seriously underestimate the impact of TBI, and any useful risk prediction model needs to provide estimates of poor neurologic outcome other than mortality. Functional outcome from TBI is typically characterized using the five-level GOS (Jennett and Bond, 1975) or the eight level GOSE (Jennett et al., 1981). In using both these schemes, several previous publications have dichotomized the scores into favourable and unfavourable outcomes, with severe disability, vegetative state (VS), and death included in the latter (Table 4).

There is a growing appreciation that such global instruments are crude metrics of outcome and disability, with substantial fine variation within outcome categories. Thus, for example, a patient in a lower "good outcome" category may be able to cope with activities of daily living, but continue to have significant cognitive deficits, 


\begin{tabular}{|c|c|c|c|c|}
\hline $\begin{array}{l}\text { Glasgow } \\
\text { Outcome } \\
\text { Scale (GOS) }\end{array}$ & $\begin{array}{l}\text { Dichotomized } \\
\text { outcome }\end{array}$ & $\begin{array}{l}\text { Glasgow Outcome } \\
\text { Scale - Extended } \\
(\text { GOSE) }\end{array}$ & Outcome description & Societal consequence \\
\hline $\begin{array}{l}\text { Good } \\
\text { outcome }\end{array}$ & $\begin{array}{l}\text { Favourable } \\
\text { outcome }\end{array}$ & $\begin{array}{l}\text { Upper good } \\
\text { outcome } \\
\text { Lower good } \\
\text { outcome }\end{array}$ & $\begin{array}{l}\text { Resumed normal life, } \\
\text { no symptoms } \\
\text { Resumed normal life, } \\
\text { some symptoms }\end{array}$ & Resumed pre-TBI life \\
\hline $\begin{array}{l}\text { Moderate } \\
\text { disability }\end{array}$ & & $\begin{array}{l}\text { Upper moderate } \\
\text { disability } \\
\text { Lower moderate } \\
\text { disability }\end{array}$ & $\begin{array}{l}\text { Limited in one or more } \\
\text { life roles } \\
\text { Unable to participate in } \\
\text { one or more life roles }\end{array}$ & $\begin{array}{l}\text { Independent, and able to } \\
\text { participate, but resumption } \\
\text { of pre-TBI life not possible }\end{array}$ \\
\hline $\begin{array}{l}\text { Severe } \\
\text { disability }\end{array}$ & $\begin{array}{l}\text { Unfavourable } \\
\text { outcome }\end{array}$ & $\begin{array}{l}\text { Upper severe } \\
\text { disability } \\
\text { Lower severe } \\
\text { disability }\end{array}$ & $\begin{array}{l}\text { Dependent, needs some } \\
\text { help } \\
\text { Dependent, needs } \\
\text { frequent help }\end{array}$ & $\begin{array}{l}\text { Recovered consciousness } \\
\text { and awareness, but } \\
\text { not independent }\end{array}$ \\
\hline $\begin{array}{l}\text { Vegetative } \\
\text { state }\end{array}$ & & $\begin{array}{l}\text { Vegetative } \\
\text { state }\end{array}$ & Unconscious/unaware & $\begin{array}{l}\text { Survival; no recovery of } \\
\text { consciousness/awareness }\end{array}$ \\
\hline Death & & Death & $\begin{array}{l}\text { Cardiac arrest due to } \\
\text { terminal extubation } \\
\text { or brain death }\end{array}$ & $\begin{array}{l}\text { Potential for organ } \\
\text { donation }\end{array}$ \\
\hline
\end{tabular}

Table 4: Outcome schemes for traumatic brain injury (TBI).

often affecting working memory, executive function, and self-regulation of impulsive behaviours, which may only be detected by formal cognitive testing. In addition, many patients experience psychiatric and psychologic problems, with depression being seen in over a third of severe TBI survivors. At the other end of the scale, there has been substantial refinement in characterization of patients with prolonged disorders of consciousness (Giacino and Kalmar, 2005; Giacino et al., 2014; Turner-Stokes, 2014). The threshold between VS and severe disability is now recognized to include discrete behavioural levels as VS patients emerge into a minimally conscious state (MCS, which is sometimes further subdivided as MCS+ and MCS-), and then make the transition from MCS to full consciousness through a transitional state. Further, these clinician reported outcomes take no account of patients' views, and there is an increasing recognition of the need to apply patient-reported outcome measures such as the Quality of Life after Brain Injury (Qolibri) scale (von Steinbuchel et al., 2010).

\section{Outcome prediction}

Accurate prediction of prognosis in TBI is important for several purposes (Lingsma et al., 2010; Maas et al., 2015). These include calibrating the expectations of patients and families, planning clinical care, accurate risk-adjusted comparative audit of clinical performance of institutions, and for efficient clinical trial design using novel techniques (such as sliding dichotomy and proportional odds approaches) (Roozenbeek et al., 2011). Unfortunately, classic risk adjustment programs commonly used in general critical care do not perform optimally in TBI (Hyam et al., 2006). The key clinical features at presentation that determine outcome in TBI are well documented, and include age, GCS score, and CT appearance. However, given the complex interactions of injury and host variables in driving outcome, a clear need exists for a prognostic scheme that integrates these factors. In 2006, a systematic review (Perel et al., 2006) concluded that most predictive models were inadequately validated, poorly presented, and based on small single-centre samples that excluded patients from low-income countries (where TBI is most common). In the last decade, two groups have used large study datasets to provide more accurate prognostic models in TBI: the International Mission on Prognosis and Analysis of Clinical Trials in TBI (IMPACT) and Medical Research Council Corticosteroid Randomization after Significant Head Injury (MRC CRASH) trial (MRC Crash Trial Collaborators, 2008; Steyerberg et al., 2008). The IMPACT authors collected data from 9205 patients with TBI enrolled in eight randomized clinical trials and three large observational studies. CRASH, the largest clinical trial ever conducted in TBI, collected data in over 10000 patients with TBI.

The CRASH dataset of patients was used to develop separate sets of risk prediction models (MRC Crash Trial Collaborators, 2008) for high-income countries, and for low-/middle-income countries. Within each of these categories, the models allow prediction either with or without knowledge of CT appearances. The models have been made publicly available on a web-based calculator, which allows entry of clinical and imaging data to produce an estimated risk of death or disability with confidence intervals for each estimate (http://crash2. lshtm.ac.uk/Risk\%20calculator/index.html). The models perform reasonably well, and the high-income 
countries model was externally validated against a large number of patients from the IMPACT database.

The IMPACT model (Steyerberg et al., 2008) predicts mortality and GOS at 6 months after injury, and was externally validated in 6681 patients from the MRC CRASH trial population. The strongest predictors of outcome were age, GCS motor score, pupil reactivity, and admission CT scan. Model performance was significantly improved by the inclusion of secondary insults (hypotension and hypoxia), and laboratory variables (blood glucose and haemoglobin). External validation against patients from the CRASH database showed reasonable performance, which improved when validation was undertaken against a subset of CRASH patients from high-income countries. Like the CRASH prediction methodology, the IMPACT model is available online, thus allowing access for risk prediction in individual subjects (http://www.tbi-impact.org/). The IMPACT model has been validated in multiple settings, and shows good discrimination of favourable and unfavourable outcomes (Maas et al., 2015), but sometimes poor calibration in new patient populations (Harrison et al., 2013), which can be substantially improved by recalibration in these contexts (Harrison et al., 2015).

Despite these advances, it is sobering to reflect that the current covariates in prognostic schemes account only for about one-third of the variance observed in TBI outcome. Advanced neuroimaging (including MRI), protein biomarkers, and genetic variation could add to the prognostic accuracy of schemes that only include simple clinical variables. Proof of such incremental benefit is now emerging, and future versions of these established prognostic schemes may integrate data from these sources.

\section{Acknowledgements}

DKM and AE are supported by a European Union Framework Program 7 grant (CENTER-TBI; agreement no. 602150). DKM is supported by funding from the National Institute for Health Research (NIHR) UK through a Senior Investigator Award, and the Cambridge NIHR Biomedical Research Centre. We would like to acknowledge the immense help provided by Joanne Outtrim and Jemma Andrews in organizing this manuscript, and Dr. Jed Hartings for providing the image in Figure 3. The Cambridge Neurosciences Critical Care Unit (NCCU) ICP/CPP protocol has been developed jointly by the NCCU and the Neurosurgical Unit at Addenbrooke's Hospital; the algorithm in Figure 10 includes input from Dr. Ronan O'Leary and Dr. Andrea Lavinio (NCCU), and David de Monteverdi-Robb (Pharmacy Department).

\section{References}

Adams JH, Jennett B, McLellan DR et al. (1999). The neuropathology of the vegetative state after head injury. J ClinPathol 52: 804-806.

Adams JH, Jennett B, Murray LS et al. (2011). Neuropathological findings in disabled survivors of a head injury. J Neurotrauma 28: 701-709.

Agrawal D, Saini R, Singh PK et al. (2016). Bedside computed tomography in traumatic brain injury: experience of 10000 consecutive cases in neurosurgery at a level 1 trauma center in India. Neurol India 64: $62-65$.

Aisiku IP, Yamal JM, Doshi P et al. (2016). The incidence of ARDS and associated mortality in severe TBI using the Berlin definition. J Trauma Acute Care Surg 80: 308-312.

Alali AS, Fowler RA, Mainprize TG et al. (2013). Intracranial pressure monitoring in severe traumatic brain injury: results from the American College of Surgeons Trauma Quality Improvement Program. J Neurotrauma 30: $1737-1746$.

Alali AS, Scales DC, Fowler RA et al. (2014). Tracheostomy timing in traumatic brain injury: a propensitymatched cohort study. J Trauma Acute Care Surg 76: 70-76. discussion 76-78.

Altmeyer W, Steven A, Gutierrez J (2016). Use of magnetic resonance in the evaluation of cranial trauma. Magn Reson Imaging Clin N Am 24: 305-323.

Alves JL (2014). Blood-brain barrier and traumatic brain injury. J Neurosci Res 92: 141-147.

Amyot F, Arciniegas DB, Brazaitis MP et al. (2015). A review of the effectiveness of neuroimaging modalities for the detection of traumatic brain injury. J Neurotrauma 32: 1693-1721.

Andelic N, Hammergren N, Bautz-Holter E et al. (2009). Functional outcome and health-related quality of life 10 years after moderate-to-severe traumatic brain injury. Acta Neurol Scand 120: 16-23.

Andelic N, Ye J, Tornas S et al. (2014). Cost-effectiveness analysis of an early-initiated, continuous chain of rehabilitation after severe traumatic brain injury. J Neurotrauma 31: 1313-1320.

Andrews PJD, Sinclair HL, Rodriguez A et al. (2015). Hypothermia for intracranial hypertension after traumatic brain injury. N Engl J Med 373: 2403-2412.

Anglin CO, Spence JS, Warner MA et al. (2013). Effects of platelet and plasma transfusion on outcome in traumatic brain injury patients with moderate bleeding diatheses. J Neurosurg 118: 676-686. 
Anke A, Andelic N, Skandsen T et al. (2015). Functional recovery and life satisfaction in the first year after severe traumatic brain injury: a prospective multicenter study of a Norwegian national cohort. J Head Trauma Rehabil 30: E38-E49.

Aries MJ, Czosnyka M, Budohoski KP et al. (2012). Continuous determination of optimal cerebral perfusion pressure in traumatic brain injury. Crit Care Med 40: 2456-2463.

Balestreri M, Czosnyka M, Hutchinson P et al. (2006). Impact of intracranial pressure and cerebral perfusion pressure on severe disability and mortality after head injury. Neurocrit Care 4: 8-13.

Bao L, Chen D, Ding L et al. (2014). Fever burden is an independent predictor for prognosis of traumatic brain injury. PLoS One 9: e90956.

Barbey AK, Colom R, Paul E et al. (2014). Preservation of general intelligence following traumatic brain injury: contributions of the Met66 brain-derived neurotrophic factor. PLoS One 9: e88733.

Batchelor JS, Grayson A (2012a). A meta-analysis to determine the effect of anticoagulation on mortality in patients with blunt head trauma. Br J Neurosurg 26: 525-530.

Batchelor JS, Grayson A (2012b). A meta-analysis to determine the effect on survival of platelet transfusions in patients with either spontaneous or traumatic antiplatelet medication-associated intracranial haemorrhage. BMJ Open 2: e000588.

Batchelor JS, Grayson A (2013). A meta-analysis to determine the effect of preinjury antiplatelet agents on mortality in patients with blunt head trauma. Br J Neurosurg 27: 12-18.

Blumbergs PC, Reilly P, Vink R (2008). Trauma. In: S Love, D Louis,DWEllison (Eds.), Greenfield's Neuropathology, 8th edn. Taylor \& Francis, London.

Bogner JA, Corrigan JD, Fugate L et al. (2001). Role of agitation in prediction of outcomes after traumatic brain injury. Am J Phys Med Rehabil 80: 636-644.

Bohmer AE, Oses JP, Schmidt AP et al. (2011). Neuronspecific enolase, S100B, and glial fibrillary acidic protein levels as outcome predictors in patients with severe traumatic brain injury. Neurosurgery 68: 1624-1630. discussion 1630-1621.

Bone LB, Johnson KD, Weigelt J et al. (1989). Early versus delayed stabilization of femoral fractures. A prospective randomized study. J Bone Joint Surg Am 71: 336-340.

Bouma GJ, Muizelaar JP, Choi SC et al. (1991). Cerebral circulation and metabolism after severe traumatic brain injury: the elusive role of ischemia. J Neurosurg 75: 685-693.

Bouma GJ, Muizelaar JP, Stringer WA et al. (1992). Ultraearly evaluation of regional cerebral blood flow in severely head-injured patients using xenon-enhanced computerized tomography. J Neurosurg 77: 360-368.

Bragge P, Synnot A, Maas AI et al. (2016). A state-of-thescience overview of randomized controlled trials evaluating acute management of moderate-to-severe traumatic brain injury. J Neurotrauma 33: 1461-1478.

Brain Trauma Foundation, American Association of Neurological Surgeons, Congress of Neurological Surgeons (2007a). Guidelines for the management of severe traumatic brain injury. J Neurotrauma 24 (Suppl 1): S1-S106.

Brain Trauma Foundation, American Association of Neurological Surgeons, Congress of Neurological Surgeons (2007b). Guidelines for the management of severe traumatic brain injury. IX. Cerebral perfusion thresholds. J Neurotrauma 24 (Suppl 1): S59-S64.

Brain Trauma Foundation, American Association of Neurological Surgeons, Congress of Neurological Surgeons (2007c). Guidelines for the management of severe traumatic brain injury. XII. Nutrition. J Neurotrauma 24 (Suppl 1): S77-S82.

Brain Trauma Foundation, American Association of Neurological Surgeons, Congress of Neurological Surgeons (2007d). Guidelines for the management of severe traumatic brain injury. XIII. Antiseizure prophylaxis. J Neurotrauma 24 (Suppl 1): S83-S86.

Brain Trauma Foundation, Surgeons, American Association of Neurological Surgeons, Congress of Neurological Surgeons (2007e). Guidelines for the management of severe traumatic brain injury. J Neurotrauma 24 (Suppl 1): S1-S106.

Brain Trauma Foundation, American Association of Neurological Surgeons, The Joint Section on Neurotrauma and Critical Care (2000). Guidelines for cerebral perfusion pressure. J Neurotrauma 17: 507-511.

Brain Trauma Foundation, American Association of Neurological Surgeons, Congress of Neurological Surgeons (2016). https://braintrauma.org/uploads/03/12/Guidelines_for_Management_of_Severe_TBI_4th_ Edition.pdf (last accessed 18th October 2016).

Brenner M, Stein DM, Hu PF et al. (2012). Traditional systolic blood pressure targets underestimate hypotension-induced secondary brain injury. J Trauma Acute Care Surg 72: 1135-1139.

Brown GC (2000). Nitric oxide as a competitive inhibitor of oxygen consumption in the mitochondrial respiratory chain. Acta Physiol Scand 168: 667-674.

Brown JB, Stassen NA, Cheng JD et al. (2010). Trauma center designation correlates with functional independence after severe but not moderate traumatic brain injury. J Trauma 69: 263-269.

Bulger EM, Nathens AB, Rivara FP et al. (2002). Management of severe head injury: institutional variations in care and effect on outcome. Crit Care Med 30: 1870-1876. 
Bullock MR, Chesnut R, Ghajar J et al. (2006). Surgical management of acute subdural haematomas. Neurosurgery 58: S16-S24. discussion Si-iv.

Bulstrode H, Nicoll JA, Hudson G et al. (2014). Mitochondrial DNA and traumatic brain injury. Ann Neurol 75: 186-195.

Butcher I, Maas AI, Lu J et al. (2007). Prognostic value of admission blood pressure in traumatic brain injury: results from the IMPACT study. J Neurotrauma 24: 294-302.

Carlson AP, Yonas H (2012). Portable head computed tomography scanner - technology and applications: experience with 3421 scans. J Neuroimaging 22: 408-415.

Caterino JM, Raubenolt A, Cudnik MT (2011). Modification of Glasgow Coma Scale criteria for injured elders. Acad Emerg Med 18: 1014-1021.

Chang BS, Lowenstein DH (2003). Practice parameter: antiepileptic drug prophylaxis in severe traumatic brain injury: report of the Quality Standards Subcommittee of the American Academy of Neurology. Neurology 60: $10-16$

Chen S, Chen Y, Xu L et al. (2015). Venous system in acute brain injury: mechanisms of pathophysiological change and function. Exp Neurol 272: 4-10.

Chesnut RM, Marshall LF, Klauber MR et al. (1993). The role of secondary brain injury in determining outcome from severe head injury. J Trauma 34: 216-222.

Chesnut RM, Temkin N, Carney N et al. (2012). A trial of intracranial-pressure monitoring in traumatic brain injury. N Engl J Med 367: 2471-2481.

Chesnut RM, Bleck TP, Citerio G et al. (2015). A consensus based interpretation of the benchmark evidence from South American trials: treatment of intracranial pressure trial. J Neurotrauma 32: 1722-1724.

Chi JH, Knudson MM, Vassar MJ et al. (2006). Prehospital hypoxia affects outcome in patients with traumatic brain injury: a prospective multicenter study. J Trauma 61: 1134-1141.

Claassen J, Vespa P, Participants in the International Multidisciplinary Consensus Conference on Multimodality Monitoring (2014). Electrophysiologic monitoring in acute brain injury. Neurocrit Care 21 (Suppl 2): S129-S147.

Clifton GL, Miller ER, Choi SC et al. (2001). Lack of effect of induction of hypothermia after acute brain injury. N Engl J Med 344: 556-563.

Clifton GL, Valadka A, Zygun D et al. (2011). Very early hypothermia induction in patients with severe brain injury (the National Acute Brain Injury Study: Hypothermia II): a randomised trial. Lancet Neurol 10: 131-139.

Coles JP, Minhas PS, Fryer TD et al. (2002). Effect of hyperventilation on cerebral blood flow in traumatic head injury: clinical relevance and monitoring correlates. Crit Care Med 30: 1950-1959.

Coles JP, Fryer TD, Smielewski P et al. (2004). Incidence and mechanisms of cerebral ischemia in early clinical head injury. Journal of Cerebral Blood Flow \& Metabolism 24: 202-211.

Coles JP, Fryer TD, Coleman MR et al. (2007). Hyperventilation following head injury: effect on ischemic burden and cerebral oxidative metabolism. Crit Care Med 35: 568-578.

Conley YP, Okonkwo DO, Deslouches S et al. (2014). Mitochondrial polymorphisms impact outcomes after severe traumatic brain injury. J Neurotrauma 31: 34-41.

Cooper DJ, Rosenfeld JV, Murray L et al. (2011). Decompressive craniectomy in diffuse traumatic brain injury. N Engl J Med 364: 1493-1502.

Corrigan JD, Cuthbert JP, Harrison-Felix C et al. (2014). US population estimates of health and social outcomes 5 years after rehabilitation for traumatic brain injury. J Head Trauma Rehabil 29: E1-E9.

MRC Crash Trial Collaborators, Perel P, Arango M et al. (2008). Predicting outcome after traumatic brain injury: practical prognostic models based on large cohort of international patients. BMJ 336: 425-429.

CRASH-2 collaborators, Roberts I, ShakurH et al. (2011). The importance of early treatment with tranexamic acid in bleeding trauma patients: an exploratory analysis of the CRASH-2 randomised controlled trial. Lancet 377: 1096-1101. 1101 e1091-1092.

CRASH-2 trial collaborators, Shakur H, Roberts I et al. (2010). Effects of tranexamic acid on death, vascular occlusive events, and blood transfusion in trauma patients with significant haemorrhage (CRASH-2): a randomised, placebo-controlled trial. Lancet 376: 23-32.

Cremer OL, Moons KG, Bouman EA et al. (2001). Long-term propofol infusion and cardiac failure in adult head-injured patients. Lancet 357: 117-118.

Cremer OL, van Dijk GW, van Wensen E et al. (2005). Effect of intracranial pressure monitoring and targeted intensive care on functional outcome after severe head injury. Crit Care Med 33: 2207-2213.

Daneshvar DH, Goldstein LE, Kiernan PT et al. (2015). Posttraumatic neurodegeneration and chronic traumatic encephalopathy. Mol Cell Neurosci 66: 81-90.

De Bonis P, Pompucci A, Mangiola A et al. (2011). Decompressive craniectomy for elderly patients with traumatic brain injury: it's probably not worth the while. J Neurotrauma 28: 2043-2048.

DeKosky ST, Blennow K, Ikonomovic MD et al. (2013). Acute and chronic traumatic encephalopathies: pathogenesis and biomarkers. Nat Rev Neurol 9: 192-200. 
Dengler B, Garvin R, Seifi A (2015). Can therapeutic hypothermia trigger propofol-related infusion syndrome? J Crit Care 30: 823-824.

Dewan Y, Komolafe EO, Mejia-Mantilla JH et al. (2012). CRASH-3 - tranexamic acid for the treatment of significant traumatic brain injury: study protocol for an international randomized, double-blind, placebocontrolled trial. Trials 13: 87.

Diamond ML, Ritter AC, Failla MD et al. (2014). IL-1b associations with posttraumatic epilepsy development: a genetics and biomarker cohort study. Epilepsia 55 (7): 1109-1119.

Diaz-Arrastia R, Wang KK, Papa L et al. (2014). Acute biomarkers of traumatic brain injury: relationship between plasma levels of ubiquitin C-terminal hydrolase-L1 and glial fibrillary acidic protein. J Neurotrauma 31: 19-25.

Ding K, Gupta PK, Diaz-Arrastia R (2016). Frontiers in neuroscience epilepsy after traumatic brain injury. In: D Laskowitz, G Grant (Eds.), Translational Research in Traumatic Brain Injury. CRC Press/Taylor and Francis, Boca Raton, FL.

Donkin JJ, Vink R (2010). Mechanisms of cerebral edema in traumatic brain injury: therapeutic developments. Curr Opin Neurol 23: 293-299.

Elf K, Nilsson P, Enblad P (2002). Outcome after traumatic brain injury improved by an organized secondary insult program and standardized neurointensive care. Crit Care Med 30: 2129-2134.

Elterman J, Brasel K, Brown S et al. (2013). Transfusion of red blood cells in patients with a prehospital Glasgow Coma Scale score of 8 or less and no evidence of shock is associated with worse outcomes. J Trauma Acute Care Surg 75: 8-14. discussion 14.

English SW, Turgeon AF, Owen E et al. (2013). Protocol management of severe traumatic brain injury in intensive care units: a systematic review. Neurocrit Care 18: 131-142.

Etemadrezaie H, Baharvahdat H, Shariati Z et al. (2007). The effect of fresh frozen plasma in severe closed head injury. Clin Neurol Neurosurg 109: 166-171.

EuroSafe (2013). Injuries in the European Union: report on injury statistics 2008-2010, EuroSafe, Amsterdam.

Fabbri A, Servadei F, Marchesini G et al. (2013). Antiplatelet therapy and the outcome of subjects with intracranial injury: the Italian SIMEU study. Crit Care 17: R53.

Fabricius M, Fuhr S, Bhatia R et al. (2006). Cortical spreading depression and peri-infarct depolarization in acutely injured human cerebral cortex. Brain 129: 778-790.

Failla MD, Burkhardt JN, Miller MA et al. (2013). Variants of SLC6A4 in depression risk following severe TBI. Brain Inj 27: 696-706.

Fakhry SM, Trask AL, Waller MA et al. (2004). Management of brain-injured patients by an evidencebased medicine protocol improves outcomes and decreases hospital charges. J Trauma 56: 492-499. discussion 499-500.

Faul M, Xu L, WaldMet al. (2010). Traumatic brain injury in the United States: emergency department visits hospitalizations and deaths 2002-2006, Centers for Disease Control and Prevention, National Center for Injury Prevention and Control, Atlanta, GA.

Fearnside MR, Cook RJ, McDougall P et al. (1993). The Westmead Head Injury Project outcome in severe head injury. A comparative analysis of pre-hospital, clinical and CT variables. Br J Neurosurg 7: 267-279.

Fehlings MG, Vaccaro A, Wilson JR et al. (2012). Early versus delayed decompression for traumatic cervical spinal cord injury: results of the Surgical Timing in Acute Spinal Cord Injury Study (STASCIS). PLoS One $7 \mathrm{e} 32037$.

Feigin VL, Theadom A, Barker-Collo S et al. (2013). Incidence of traumatic brain injury in New Zealand: a population-based study. Lancet Neurol 12: 53-64.

Finfer S, Chittock D, Li Y et al. (2015). Intensive versus conventional glucose control in critically ill patients with traumatic brain injury: long-term follow-up of a subgroup of patients from the NICE-SUGAR study. Intensive Care Med 41: 1037-1047.

Fleminger S, Greenwood RJ, Oliver DL (2006). Pharmacological management for agitation and aggression in people with acquired brain injury. Cochrane Database Syst Rev Cd003299.

Fugate LP, Spacek LA, Kresty LA et al. (1997). Measurement and treatment of agitation following traumatic brain injury: II. A survey of the Brain Injury Special Interest Group of the American Academy of Physical Medicine and Rehabilitation. Arch Phys Med Rehabil 78: 924-928.

Fuller G, Bouamra O, WoodfordMet al. (2011). The effect of specialist neurosciences care on outcome in adult severe head injury: a cohort study. J Neurosurg Anesthesiol 23: 198-205.

Galanaud D, Perlbarg V, Gupta R et al. (2012). Assessment of white matter injury and outcome in severe brain trauma: a prospective multicenter cohort.Anesthesiology 117: 1300-1310.

Giacino JT, Kalmar K (2005). Diagnostic and prognostic guidelines for the vegetative and minimally conscious states. Neuropsychol Rehabil 15: 166-174.

Giacino JT, Whyte J, Bagiella E et al. (2012). Placebo controlled trial of amantadine for severe traumatic brain injury. N Engl J Med 366: 819-826. 
Giacino JT, Fins JJ, Laureys S et al. (2014). Disorders of consciousness after acquired brain injury: the state of the science. Nat Rev Neurol 10: 99-114.

Goldschlager T, Rosenfeld JV, Winter CD (2007). 'Talk and die' patients presenting to a major trauma centre over a 10 year period: a critical review. J Clin Neurosci 14: 618-623. discussion 624.

Graham DI, Adams JH, Doyle D (1978). Ischaemic brain damage in fatal non-missile head injuries. J Neurol Sci 39: 213-234.

Graham DI, Ford I, Adams JH et al. (1989). Ischaemic brain damage is still common in fatal non-missile head injury. J Neurol Neurosurg Psychiatry 52: 346-350.

Grande PO (2006). The "Lund concept" for the treatment of severe head trauma - physiological principles and clinical application. Intensive Care Med 32: 1475-1484.

Grandhi R, Harrison G, Voronovich Z et al. (2015). Preinjury warfarin, but not antiplatelet medications, increases mortality in elderly traumatic brain injury patients. J Trauma Acute Care Surg 78: 614-621.

Greenwald BD, Hammond FM, Harrison-Felix C et al. (2015). Mortality following traumatic brain injury among individuals unable to follow commands at the time of rehabilitation admission: a National Institute on Disability and Rehabilitation Research traumatic brain injury model systems study. J Neurotrauma 32 : 1883-1892.

Greuters S, van den Berg A, Franschman G et al. (2011). Acute and delayed mild coagulopathy are related to outcome in patients with isolated traumatic brain injury. Crit Care 15: R2.

Gupta AK, Menon DK, Czosnyka M et al. (1997). Thresholds for hypoxic cerebral vasodilation in volunteers. Anesth Analg. 85 (4): 817-820.

Hackam DG, Mrkobrada M (2012). Selective serotonin reuptake inhibitors and brain hemorrhage: a metaanalysis. Neurology 79: 1862-1865.

Hadjigeorgiou GM, Paterakis K, Dardiotis E et al. (2005). IL-1RN and IL-1B gene polymorphisms and cerebral hemorrhagic events after traumatic brain injury. Neurology 65: 1077-1082.

Hajjar LA, Vincent JL, Galas FR et al. (2010). Transfusion requirements after cardiac surgery: the TRACS randomized controlled trial. JAMA 304: 1559-1567.

Harhangi BS, Kompanje EJ, Leebeek FW et al. (2008). Coagulation disorders after traumatic brain injury. Acta Neurochir (Wien) 150: 165-175. discussion 175.

Harrison DA, Prabhu G, Grieve R et al. (2013). Risk Adjustment In Neurocritical care (RAIN) - prospective validation of risk prediction models for adult patients with acute traumatic brain injury to use to evaluate the optimum location and comparative costs of neurocritical care: a cohort study. Health Technol Assess 17: vii-viii. $1-350$.

Harrison DA, Griggs KA, Prabhu G et al. (2015). External validation and recalibration of risk prediction models for acute traumatic brain injury among critically ill adult patients in the United Kingdom. J Neurotrauma 32: 1522-1537.

Hartings JA, Bullock MR, Okonkwo DO et al. (2011a). Spreading depolarisations and outcome after traumatic brain injury: a prospective observational study. Lancet Neurol 10: 1058-1064.

Hartings JA, Watanabe T, Bullock MR et al. (2011b). Spreading depolarizations have prolonged direct current shifts and are associated with poor outcome in brain trauma. Brain 134: 1529-1540.

Hartings JA, Wilson JA, Hinzman JM et al. (2014). Spreading depression in continuous electroencephalography of brain trauma. Ann Neurol 76: 681-694.

Hawryluk G, Whetstone W, Saigal R et al. (2015). Mean arterial blood pressure correlates with neurological recovery after human spinal cord injury: analysis of high frequency physiologic data. J Neurotrauma 32 : 1958-1967.

Hay JR, Johnson VE, Young AM et al. (2015). Blood-brain barrier disruption is an early event that may persist for many years after traumatic brain injury in humans. J Neuropathol Exp Neurol 74: 1147-1157.

Hebert PC, Wells G, Blajchman MA et al. (1999). A multicenter, randomized, controlled clinical trial of transfusion requirements in critical care. Transfusion Requirements in Critical Care Investigators, Canadian Critical Care Trials Group. N Engl J Med 340: 409-417.

Hertle DN, Dreier JP,Woitzik J et al. (2012a). Effect of analgesics and sedatives on the occurrence of spreading depolarizations accompanying acute brain injury. Brain 135: 2390-2398.

Hertle DN, Dreier JP, Woitzik J et al. (2012b). Effect of analgesics and sedatives on the occurrence of spreading depolarizations accompanying acute brain injury. Brain 135: 2390-2398.

Hifumi T, Kuroda Y, Kawakita K et al. (2016). Fever control management is preferable to mild therapeutic hypothermia in traumatic brain injury patients with Abbreviated Injury Scale 3-4: a multi-center, randomized controlled trial. J Neurotrauma 33: 1047-1053.

Hill DA, Abraham KJ, West RH (1993). Factors affecting outcome in the resuscitation of severely injured patients. Aust N Z J Surg 63: 604-609.

Hill CS, Coleman MP, Menon DK (2016). Traumatic axonal injury: mechanisms and translational opportunities. Trends Neurosci 39: 311-324. 
Hinzman JM, Wilson JA, Mazzeo AT et al. (2016). Excitotoxicity and metabolic crisis are associated with spreading depolarizations in severe traumatic brain injury patients. J Neurotrauma (epub ahead of print).

Hoffman AN, Cheng JP, Zafonte RD et al. (2008). Administration of haloperidol and risperidone after neurobehavioral testing hinders the recovery of traumatic brain injury-induced deficits. Life Sci 83: 602-607.

Hoh NZ, Wagner AK, Alexander SA et al. (2010). BCL2 genotypes: functional and neurobehavioral outcomes after severe traumatic brain injury. J Neurotrauma 27: 1413-1427.

Honda M, Tsuruta R, Kaneko T et al. (2010). Serum glial fibrillary acidic protein is a highly specific biomarker for traumatic brain injury in humans compared with S-100B and neuron-specific enolase. J Trauma 69: 104-109.

Hoyt DB (2004). A clinical review of bleeding dilemmas in trauma. Semin haematol 41: 40-43.

Huber-Wagner S, Lefering R, Qvick LM et al. (2009). Effect of whole-body CT during trauma resuscitation on survival: a retrospective, multicentre study. Lancet 373: 1455-1461.

Hutchinson PJ, Hutchinson DB, Barr RH et al. (2000). A new cranial access device for cerebral monitoring. Br J Neurosurg 14: 46-48.

Hutchinson PJ, Kolias AG, Czosnyka M et al. (2013). Intracranial pressure monitoring in severe traumatic brain injury. BMJ 346: f1000.

Hutchinson PJ, Jalloh I, Helmy A et al. (2015). Consensus statement from the 2014 International Microdialysis Forum. Intensive Care Med 41: 1517-1528.

Hutchinson PJ, Kolias AG, Timofeev IS et al. (2016). Trial of Decompressive craniectomy for traumatic intracranial hypertension. N Engl J Med 375: 1119-1130.

Hyam JA, Welch CA, Harrison DA et al. (2006). Case mix, outcomes and comparison of risk prediction models for admissions to adult, general and specialist critical care units for head injury: a secondary analysis of the ICNARC Case Mix Programme Database. Crit Care 10 (Suppl 2): S2.

Hyder AA, Wunderlich CA, Puvanachandra P et al. (2007). The impact of traumatic brain injuries: a global perspective. NeuroRehabilitation 22: 341-353.

ICNARC (2015). Annual Quality Report 2013/14 for adult, neurocritical (neuro, combined ICU/neuro) care, Intensive Care National Audit and Research Centre, London.

Inaba K, Rizoli S, Veigas PV et al. (2015). 2014 Consensus conference on viscoelastic test-based transfusion guidelines for early trauma resuscitation: report of the panel. J Trauma Acute Care Surg 78: 1220-1229.

Jamjoom AA, Jamjoom AB (2013). Safety and efficacy of early pharmacological thromboprophylaxis in traumatic brain injury: systematic review and meta-analysis. J Neurotrauma 30: 503-511.

Janowitz T, Menon DK (2010). Exploring new routes for neuroprotective drug development in traumatic brain injury. Sci Transl Med 2: 27rv21.

Jennett B, BondM(1975). Assessment of outcome after severe brain damage. Lancet 1: 480-484.

Jennett B, Snoek J, Bond MR et al. (1981). Disability after severe head injury: observations on the use of the Glasgow Outcome Scale. J Neurol Neurosurg Psychiatry 44: 285-293.

Jeremitsky E, Omert L, Dunham CM et al. (2003). Harbingers of poor outcome the day after severe brain injury: hypothermia, hypoxia, and hypoperfusion. J Trauma 54: 312-319.

Jones PA, Andrews PJ, Midgley S et al. (1994). Measuring the burden of secondary insults in head-injured patients during intensive care. J Neurosurg Anesthesiol 6: 4-14.

Joseph B, Pandit V, Aziz H et al. (2014). Clinical outcomes in traumatic brain injury patients on preinjury clopidogrel: a prospective analysis. J Trauma Acute Care Surg 76: 817-820.

Kamel H, Navi BB, Nakagawa K et al. (2011). Hypertonic saline versus mannitol for the treatment of elevated intracranial pressure: a meta-analysis of randomized clinical trials. Crit Care Med 39: 554-559.

Karabinis A, Mandragos K, Stergiopoulos S et al. (2004). Safety and efficacy of analgesia-based sedation with remifentanil versus standard hypnotic-based regimens in intensive care unit patients with brain injuries: a randomised, controlled trial [ISRCTN50308308]. Crit Care 8: R268-R280.

Kasprowicz M, Burzynska M, Melcer T et al. (2016). A comparison of the Full Outline of UnResponsiveness (FOUR) score and Glasgow Coma Score (GCS) in predictive modelling in traumatic brain injury. Br J Neurosurg 30: $211-220$.

Kawamata T, Katayama Y, Aoyama N et al. (2000). Heterogeneous mechanisms of early edema formation in cerebral contusion: diffusion MRI and ADC mapping study. Acta Neurochir Suppl 76: 9-12.

Kawata K, Liu CY, Merkel SF et al. (2016). Blood biomarkers for brain injury: what are we measuring? Neurosci Biobehav Rev 68: 460-473.

Kehoe A, Rennie S, Smith JE (2015). Glasgow Coma Scale is unreliable for the prediction of severe head injury in elderly trauma patients. Emerg Med J 32: 613-615.

Kelly DF, Kordestani RK, Martin NA et al. (1996). Hyperemia following traumatic brain injury: relationship to intracranial hypertension and outcome. J Neurosurg 85: 762-771.

Kenney K, Amyot F, Haber M et al. (2016). Cerebral vascular injury in traumatic brain injury. Exp Neurol 275 (Pt 3): 353-366. 
KimJ, KempS, KullasKet al. (2013). Injury patterns in patients who "talk and die". J Clin Neurosci 20: $1697-1701$.

Kirkman MA, Jenks T, Bouamra O et al. (2013). Increased mortality associated with cerebral contusions following trauma in the elderly: bad patients or bad management? J Neurotrauma 30: 1385-1390.

Kline AE, Hoffman AN, Cheng JP et al. (2008). Chronic administration of antipsychotics impede behavioral recovery after experimental traumatic brain injury. Neurosci Lett 448: 263-267.

Kochanek PM, Jackson TC, Ferguson NM et al. (2015). Emerging therapies in traumatic brain injury. Semin Neurol 35: 83-100.

Korley FK, Diaz-Arrastia R, Wu AH et al. (2016). Circulating brain-derived neurotrophic factor has diagnostic and prognostic value in traumatic brain injury. J Neurotrauma 33: 215-225.

Krajcova A, Waldauf P, Andel M et al. (2015). Propofol infusion syndrome: a structured review of experimental studies and 153 published case reports. Crit Care 19: 398.

Kramer AH, Roberts DJ, Zygun DA (2012). Optimal glycemic control in neurocritical care patients: a systematic review and meta-analysis. Crit Care 16: R203.

Krishnamoorthy V, Vavilala MS, Mills B et al. (2015). Demographic and clinical risk factors associated with hospital mortality after isolated severe traumatic brain injury: a cohort study. J Intensive Care 3: 46.

Krishnamurthy K, Laskowitz DT (2015). Cellular and molecular mechanisms of secondary neuronal injury following traumatic brain injury. Translational Research in Traumatic Brain Injury. CRC Press, Boca Raton, FL.

Krueger F, Pardini M, Huey ED et al. (2011). The role of the Met66 brain-derived neurotrophic factor allele in the recovery of executive functioning after combat-related traumatic brain injury. J Neurosci 31: 598-606.

Kucinski T, Vaterlein O, Glauche V et al. (2002). Correlation of apparent diffusion coefficient and computed tomography density in acute ischemic stroke. Stroke 33: 1786-1791.

Kulbe JR, Geddes JW (2016). Current status of fluid biomarkers in mild traumatic brain injury. Exp Neurol 275 (Pt 3): 334-352.

Laroche M, Kutcher ME, Huang MC et al. (2012). Coagulopathy after traumatic brain injury. Neurosurgery 70: $1334-1345$.

Lawrence DW, Comper P, Hutchison MG et al. (2015). The role of apolipoprotein E episilon (epsilon)-4 allele on outcome following traumatic brain injury: a systematic review. Brain Inj 29: 1018-1031.

Lazaridis C, Neyens R, Bodle J et al. (2013). High-osmolarity saline in neurocritical care: systematic review and metaanalysis. Crit Care Med 41: 1353-1360.

Lazaridis C, DeSantis SM, Smielewski P et al. (2014). Patient specific thresholds of intracranial pressure in severe traumatic brain injury. J Neurosurg 120: 893-900.

Le Roux P, Menon DK, Citerio G et al. (2014). The International Multidisciplinary Consensus Conference on Multimodality Monitoring in Neurocritical Care: a list of recommendations and additional conclusions: a statement for healthcare professionals from the Neurocritical Care Society and the European Society of Intensive Care Medicine. Neurocrit Care 21 (Suppl 2): S282-S296.

Leal-Noval SR, Munoz-Serrano A, Arellano-Orden V et al. (2016). Effects of red blood cell transfusion on long-term disability of patients with traumatic brain injury. Neurocrit Care 24: 371-380.

Lee JH, Martin NA, Alsina G et al. (1997). Hemodynamically significant cerebral vasospasm and outcome after head injury: a prospective study. J Neurosurg 87: 221-233.

Lee JH, Kelly DF, OertelMet al. (2001). Carbon dioxide reactivity, pressure autoregulation, and metabolic suppression reactivity after head injury: a transcranial Doppler study. J Neurosurg 95: 222-232.

Lequerica AH, Rapport LJ, Loeher K et al. (2007). Agitation in acquired brain injury: impact on acute rehabilitation therapies. J Head Trauma Rehabil 22: 177-183.

Levy M, Berson A, Cook T et al. (2005). Treatment of agitation following traumatic brain injury: a review of the literature. NeuroRehabilitation 20: 279-306.

Levy AS, Salottolo K, Bar-Or R et al. (2010). Pharmacologic thromboprophylaxis is a risk factor for hemorrhage progression in a subset of patients with traumatic brain injury. J Trauma 68: 886-894.

Li J, Jiang JY (2012). Chinese Head Trauma Data Bank: effect of hyperthermia on the outcome of acute head trauma patients. J Neurotrauma 29: 96-100.

Li M, Chen T, Chen SD et al. (2015). Comparison of equimolar doses of mannitol and hypertonic saline for the treatment of elevated intracranial pressure after traumatic brain injury: a systematic review and metaanalysis. Medicine (Baltimore) 94. e736.

Lingsma HF, Roozenbeek B, Steyerberg EW et al. (2010). Early prognosis in traumatic brain injury: from prophecies to predictions. Lancet Neurol 9: 543-554.

Lipsky RH, Sparling MB, Ryan LM et al. (2005). Association of COMT Val158Met genotype with executive functioning following traumatic brain injury. J Neuropsychiatry Clin Neurosci 17: 465-471.

Logsdon AF, Lucke-Wold BP, Turner RCet al. (2015). Role of microvascular disruption in brain damage from traumatic brain injury. Compr Physiol 5: 1147-1160. 
Lustenberger T, Talving P, Kobayashi L et al. (2010). Time course of coagulopathy in isolated severe traumatic brain injury. Injury 41: 924-928.

Maas AI, Hukkelhoven CW, Marshall LF et al. (2005). Prediction of outcome in traumatic brain injury with computed tomographic characteristics: a comparison between the computed tomographic classification and combinations of computed tomographic predictors. Neurosurgery 57: 1173-1182. discussion 1173-1182.

Maas AI, Menon DK, Lingsma HF et al. (2012). Re-orientation of clinical research in traumatic brain injury: report of an international workshop on comparative effectiveness research. J Neurotrauma 29: 32-46.

Maas AI, Lingsma HF, Roozenbeek B (2015). Predicting outcome after traumatic brain injury. Handb Clin Neurol 128: 455-474.

Macmillan CS, Andrews PJ, Easton VJ (2001). Increased jugular bulb saturation is associated with poor outcome in traumatic brain injury. J Neurol Neurosurg Psychiatry 70: 101-104.

Maegele M (2013). Coagulopathy after traumatic brain injury: incidence, pathogenesis, and treatment options. Transfusion 53 (Suppl 1): 28s-37s.

Maekawa T, Yamashita S, Nagao S et al. (2015). Prolonged mild therapeutic hypothermia versus fever control with tight hemodynamic monitoring and slow rewarming in patients with severe traumatic brain injury: a randomized controlled trial. J Neurotrauma 32: 422-429.

Magnoni S, Tedesco C, Carbonara M et al. (2012). Relationship between systemic glucose and cerebral glucose is preserved in patients with severe traumatic brain injury, but glucose delivery to the brain may become limited when oxidative metabolism is impaired: implications for glycemic control. Crit Care Med 40: $1785-1791$.

Majdan M, Mauritz W, Wilbacher I et al. (2013). Barbiturates use and its effects in patients with severe traumatic brain injury in five European countries. J Neurotrauma 30: 23-29.

Manley G, Knudson MM, Morabito D et al. (2001). Hypotension, hypoxia, and head injury: frequency, duration, and consequences. Arch Surg 136: 1118-1123.

Mannion RJ, Cross J, Bradley P et al. (2007). Mechanism based MRI classification of traumatic brainstem injury and its relationship to outcome. J Neurotrauma 24: 128-135.

Marmarou A, Signoretti S, Fatouros PP et al. (2006). Predominance of cellular edema in traumatic brain swelling in patients with severe head injuries. J Neurosurg 104: 720-730.

Martin NA, Patwardhan RV, Alexander MJ et al. (1997). Characterization of cerebral hemodynamic phases following severe head trauma: hypoperfusion, hyperemia, and vasospasm. J Neurosurg 87: 9-19.

Masel BE (2015). The chronic consequences of neurotrauma. J Neurotrauma 32: 1833.

Maxwell WL, Pennington K, MacKinnon MA et al. (2004). Differential responses in three thalamic nuclei in moderately disabled, severely disabled and vegetative patients after blunt head injury. Brain 127: 2470-2478.

McAllister TW, Flashman LA, Harker Rhodes C et al. (2008). Single nucleotide polymorphisms in ANKK1 and the dopamine D2 receptor gene affect cognitive outcome shortly after traumatic brain injury: a replication and extension study. Brain Inj 22: 705-714.

McAllister TW, Tyler AL, Flashman LA et al. (2012). Polymorphisms in the brain-derived neurotrophic factor gene influence memory and processing speed one month after brain injury. J Neurotrauma 29: 1111-1118.

McHugh GS, Engel DC, Butcher I et al. (2007). Prognostic value of secondary insults in traumatic brain injury: results from the IMPACT study. J Neurotrauma 24: 287-293.

McIntyre LA, Fergusson DA, Hutchison JS et al. (2006). Effect of a liberal versus restrictive transfusion strategy on mortality in patients with moderate to severe head injury. Neurocrit Care 5: 4-9.

McMillan TM, Teasdale GM, Weir CJ et al. (2011). Death after head injury: the 13 year outcome of a case control study. J Neurol Neurosurg Psychiatry 82: 931-935.

McMillan TM, Teasdale GM, Stewart E (2012). Disability in young people and adults after head injury: 12-14 year follow-up of a prospective cohort. J Neurol Neurosurg Psychiatry 83: 1086-1091.

McMillan TM, Weir CJ, Wainman-Lefley J (2014). Mortality and morbidity 15 years after hospital admission with mild head injury: a prospective case-controlled population study. J Neurol Neurosurg Psychiatry 85: $1214-1220$.

Meier R, Bechir M, Ludwig S et al. (2008). Differential temporal profile of lowered blood glucose levels (3.5 to $6.5 \mathrm{mmol} / \mathrm{l}$ versus 5 to $8 \mathrm{mmol} / \mathrm{l}$ ) in patients with severe traumatic brain injury. Crit Care 12: R98.

Meierhans R, Bechir M, Ludwig S et al. (2010). Brain metabolism is significantly impaired at blood glucose below $6 \mathrm{mM}$ and brain glucose below $1 \mathrm{mM}$ in patients with severe traumatic brain injury. Crit Care 14: R13.

Menon DK, Maas AI (2015). Traumatic brain injury in 2014. Progress, failures and new approaches for TBI research. Nat Rev Neurol 11: 71-72.

Menon DK, Coles JP, Gupta AK et al. (2004). Diffusion limited oxygen delivery following head injury. Crit Care Med 32: 1384-1390.

Menon DK, Schwab K, Wright DW et al. (2010). Position statement: definition of traumatic brain injury. Arch Phys Med Rehabil 91: 1637-1640.

Miller MP, Trujillo TC, Nordenholz KE (2014). Practical considerations in emergency management of bleeding in the setting of target-specific oral anticoagulants. Am J Emerg Med 32: 375-382. 
Moen KG, Skandsen T, Folvik Met al. (2012). A longitudinal MRI study of traumatic axonal injury in patients with moderate and severe traumatic brain injury. J Neurol Neurosurg Psychiatry 83: 1193-1200.

Moen KG, Brezova V, Skandsen T et al. (2014). Traumatic axonal injury: the prognostic value of lesion load in corpus callosum, brain stem, and thalamus in different magnetic resonance imaging sequences. J Neurotrauma 31: $1486-1496$.

Mondello S, Papa L, Buki A et al. (2011). Neuronal and glial markers are differently associated with computed tomography findings and outcome in patients with severe traumatic brain injury: a case control study. Crit Care 15: R156.

Mondello S, Jeromin A, Buki A et al. (2012). Glial neuronal ratio: a novel index for differentiating injury type in patients with severe traumatic brain injury. J Neurotrauma 29: 1096-1104.

Morrison CA, Carrick MM, Norman MA et al. (2011). Hypotensive resuscitation strategy reduces transfusion requirements and severe postoperative coagulopathy in trauma patients with hemorrhagic shock: preliminary results of a randomized controlled trial. J Trauma 70: 652-663.

Muizelaar JP, Marmarou A, Ward JD et al. (1991). Adverse effects of prolonged hyperventilation in patients with severe head injury: a randomized clinical trial. J Neurosurg 75: 731-739.

Munoz-Bendix C, Beseoglu K, Kram R (2015). Extracorporeal decarboxylation in patients with severe traumatic brain injury and ARDS enables effective control of intracranial pressure. Crit Care 19: 381.

Mura E, Pistoia F, SaraMet al. (2014). Pharmacological modulation of the state of awareness in patients with disorders of consciousness: an overview. Curr Pharm Des 20: 4121-4139.

Murray GD, Butcher I, McHugh GS et al. (2007). Multivariable prognostic analysis in traumatic brain injury: results from the IMPACT study. J Neurotrauma 24: 329-337.

Narayan RK, Maas AI, Marshall LF et al. (2008). Recombinant factor VIIA in traumatic intracerebral hemorrhage: results of a dose-escalation clinical trial. Neurosurgery 62: 776-786. discussion 786-778.

National Research Council Committee on A Framework for Developing a New Taxonomy of Disease (2011). The National Academies Collection: Reports funded by National Institutes of Health. Toward Precision Medicine: Building a Knowledge Network for Biomedical Research and a New Taxonomy of Disease. National Academies Press (US) National Academy of Sciences, Washington (DC).

Newcombe VF, Williams GB, Nortje J et al. (2007). Analysis of acute traumatic axonal injury using diffusion tensor imaging. Br J Neurosurg 21: 340-348.

Newell DW, Aaslid R, Stooss R et al. (1997). Evaluation of hemodynamic responses in head injury patients with transcranial Doppler monitoring. Acta Neurochir (Wien) 139: 804-817.

Nortje J, Coles JP, Timofeev I et al. (2008). Effect of hyperoxia on regional oxygenation and metabolism after severe traumatic brain injury: preliminary findings. Crit Care Med. 36 (1): 273-281.

Nyam TTE, Ao KH, Hung SY et al. (2017). FOUR Score predicts early outcome in patients after traumatic brain Injury. Neurocrit Care, in press.

O'Boynick CP, Kurd MF, Darden 2nd BV et al. (2014). Timing of surgery in thoracolumbar trauma: is early intervention safe? Neurosurg Focus 37: E7.

Oddo M, Schmidt JM, Carrera E et al. (2008). Impact of tight glycemic control on cerebral glucose metabolism after severe brain injury: a microdialysis study. Crit Care Med 36: 3233-3238.

Oddo M, Bosel J, Participants in the International Multidisciplinary Consensus Conference on Multimodality Monitoring (2014). Monitoring of brain and systemic oxygenation in neurocritical care patients. Neurocrit Care 21 (Suppl 2): S103-S120.

Oddo M, Crippa IA, Mehta S et al. (2016). Optimizing sedation in patients with acute brain injury. Crit Care 20: 128.

Oertel M, Boscardin WJ, Obrist WD et al. (2005). Posttraumatic vasospasm: the epidemiology, severity, and time course of an underestimated phenomenon: a prospective study performed in 299 patients. J Neurosurg 103: $812-824$.

Okasha AS, Fayed AM, Saleh AS (2014). The FOUR score predicts mortality, endotracheal intubation and ICU length of stay after traumatic brain injury. Neurocrit Care 21: 496-504.

Okonkwo DO, Yue JK, Puccio AM et al. (2013). GFAP-BDP as an acute diagnostic marker in traumatic brain injury: results from the prospective transforming research and clinical knowledge in traumatic brain injury study. J Neurotrauma 30: 1490-1497.

O'Leary R, Hutchinson PJ, Menon D (2016). Hypothermia for Intracranial Hypertension after Traumatic Brain Injury. N Engl J Med 374: 1383-1384.

Olivecrona M, Zetterlund B, Rodling-Wahlstrom M et al. (2009). Absence of electroencephalographic seizure activity in patients treated for head injury with an intracranial pressure-targeted therapy. J Neurosurg 110: 300-305.

Pajoumand M, Kufera JA, Bonds BW et al. (2016). Dexmedetomidine as an adjunct for sedation in patients with traumatic brain injury. J Trauma Acute Care Surg 81: 345-351. 
Papa L, Lewis LM, Falk JL et al. (2012). Elevated levels of serum glial fibrillary acidic protein breakdown products in mild and moderate traumatic brain injury are associated with intracranial lesions and neurosurgical intervention. Ann Emerg Med 59: 471-483.

Pape HC, Tornetta 3rd P, Tarkin I et al. (2009). Timing of fracture fixation in multitrauma patients: the role of early total care and damage control surgery. J Am Acad Orthop Surg 17: 541-549.

Parizel PM, Van Goethem JW, Ozsarlak O et al. (2005). New developments in the neuroradiological diagnosis of craniocerebral trauma. Eur Radiol 15: 569-581.

Parkin M, Hopwood S, Jones DA et al. (2005). Dynamic changes in brain glucose and lactate in pericontusional areas of the human cerebral cortex, monitored with rapid sampling on-line microdialysis: relationship with depolarisation-like events. J Cereb Blood Flow Metab 25: 402-413.

Pasco A, Ter Minassian A, Chapon C et al. (2006). Dynamics of cerebral edema and the apparent diffusion coefficient of water changes in patients with severe traumatic brain injury. A prospective MRI study. Eur Radiol 16: 1501-1508.

Patel HC, Menon DK, Tebbs S et al. (2002). Specialist neurocritical care and outcome from head injury. Intensive Care Med 28: 547-553.

Patel HC, Bouamra O, Woodford M et al. (2005). Trends in head injury outcome from 1989 to 2003 and the effect of neurosurgical care: an observational study. Lancet 366: 1538-1544.

Pelinka LE, Kroepfl A, LeixneringMet al. (2004). GFAP versus S100B in serum after traumatic brain injury: relationship to brain damage and outcome. J Neurotrauma 21: 1553-1561.

Perel P, Edwards P, Wentz R et al. (2006). Systematic review of prognostic models in traumatic brain injury. BMC Med Inform Decis Mak 6: 38.

Perel P, Al-Shahi Salman R, Kawahara T et al. (2012). CRASH-2 (Clinical Randomisation of an Antifibrinolytic in Significant Haemorrhage) intracranial bleeding study: the effect of tranexamic acid in traumatic brain injury - a nested randomised, placebo-controlled trial. Health Technol Assess 16: iii-xii. 1-54.

Peterson EC, Chesnut RM (2011). Talk and die revisited: bifrontal contusions and late deterioration. J Trauma 71: 1588-1592.

Ponsford J, McLaren A, Schonberger M et al. (2011). The association between apolipoprotein E and traumatic brain injury severity and functional outcome in a rehabilitation sample. J Neurotrauma 28: 1683-1692.

Pretz CR, Dams-O'ConnorK(2013). Longitudinal description of the Glasgow Outcome Scale-Extended for individuals in the traumatic brain injury model systems national database: a National Institute on Disability and Rehabilitation Research traumatic brain injury model systems study. Arch Phys Med Rehabil 94: 2486-2493.

Price L, Wilson C, Grant G (2015). Blood-brain barrier pathophysiology following traumatic brain injury. Translational Research in Traumatic Brain Injury. CRC Press, Boca Raton, FL.

Pugh MJ, Orman JA, Jaramillo CA et al. (2015). The prevalence of epilepsy and association with traumatic brain injury in veterans of the Afghanistan and Iraq wars. J Head Trauma Rehabil 30: 29-37.

Puljula J, Vaaramo K, Tetri S et al. (2016). Risk for all-cause and traumatic death in head trauma subjects: a prospective population-based case-control follow-up study. Ann Surg 263: 1235-1239.

Raymont V, Greathouse A, Reding K et al. (2008). Demographic, structural and genetic predictors of late cognitive decline after penetrating head injury. Brain 131: 543-558.

Reilly PL, Graham DI, Adams JH et al. (1975). Patients with head injury who talk and die. Lancet 2: $375-377$.

Riker RR, Fugate JEParticipants in the International Multidisciplinary Consensus Conference on Multimodality Monitoring (2014). Clinical monitoring scales in acute brain injury: assessment of coma, pain, agitation, and delirium. Neurocrit Care 21 (Suppl 2): S27-S37.

Rincon F, Kang J, Vibbert M et al. (2014). Significance of arterial hyperoxia and relationship with case fatality in traumatic brain injury: a multicentre cohort study. J Neurol Neurosurg Psychiatry 85 (7): $799-805$.

Rizk EB, Patel AS, Stetter CM et al. (2011). Impact of tracheostomy timing on outcome after severe head injury. Neurocrit Care 15: 481-489.

Roberts I, Sydenham E (2012). Barbiturates for acute traumatic brain injury. Cochrane Database Syst Rev 12: Cd000033.

Robertson CS, Valadka AB, Hannay HJ et al. (1999). Prevention of secondary ischemic insults after severe head injury. Crit Care Med 27: 2086-2095.

Robertson CS, Hannay HJ, Yamal JM et al. (2014). Effect of erythropoietin and transfusion threshold on neurological recovery after traumatic brain injury: a randomized clinical trial. JAMA 312: 36-47.

Rockswold SB, Rockswold GL, Zaun DA et al. (2013). A prospective, randomized Phase II clinical trial to evaluate the effect of combined hyperbaric and normobaric hyperoxia on cerebral metabolism, intracranial pressure, oxygen toxicity, and clinical outcome in severe traumatic brain injury. J Neurosurg. 118 (6): 1317-1328.

Romner B, Bellner J, Kongstad P et al. (1996). Elevated transcranial Doppler flow velocities after severe head injury: cerebral vasospasm or hyperemia? J Neurosurg 85: 90-97.

Ronne-Engstrom E, Winkler T (2006). Continuous EEG monitoring in patients with traumatic brain injury reveals a high incidence of epileptiform activity. Acta Neurol Scand 114: 47-53. 
Roozenbeek B, Lingsma HF, Perel P et al. (2011). The added value of ordinal analysis in clinical trials: an example in traumatic brain injury. Crit Care 15: R127.

Roozenbeek B, Maas AI, Menon DK (2013). Changing patterns in the epidemiology of traumatic brain injury. Nat Rev Neurol 9: 231-236.

Rosenthal G, Hemphill 3rd JC, Sorani M et al. (2008). Brain tissue oxygen tension is more indicative of oxygen diffusion than oxygen delivery and metabolism in patients with traumatic brain injury. Crit Care Med 36: $1917-1924$.

Rostami E (2014). Glucose and the injured brain-monitored in the neurointensive care unit. Front Neurol 5: 91 .

Rostami E, Engquist H, Enblad P (2014). Imaging of cerebral blood flow in patients with severe traumatic brain injury in the neurointensive care. Front Neurol 5: 114.

Ryu JH, Walcott BP, Kahle KT et al. (2013). Induced and sustained hypernatremia for the prevention and treatment of cerebral edema following brain injury. Neurocrit Care 19: 222-231.

Saatman KE, Duhaime AC, Bullock R et al. (2008). Classification of traumatic brain injury for targeted therapies. J Neurotrauma 25: 719-738.

Sacho RH, Vail A, Rainey T et al. (2010). The effect of spontaneous alterations in brain temperature on outcome: a prospective observational cohort study in patients with severe traumatic brain injury. J Neurotrauma 27: $2157-2164$.

Sadaka F, Patel D, Lakshmanan R (2012). The FOUR score predicts outcome in patients after traumatic brain injury. Neurocrit Care 16: 95-101.

Sanchez-Izquierdo-Riera JA, Caballero-Cubedo RE, Perez-Vela JL et al. (1998). Propofol versus midazolam: safety and efficacy for sedating the severe trauma patient. Anesth Analg 86: 1219-1224.

Sarrafzadeh AS, Peltonen EE, Kaisers U et al. (2001). Secondary insults in severe head injury - do multiply injured patients do worse? Crit Care Med 29: 1116-1123.

Saxena M, Andrews PJ, Cheng A et al. (2014). Modest cooling therapies (35 masculineC to 37.5 masculineC) for traumatic brain injury. Cochrane Database Syst Rev: Cd006811.

Schaible EV, Thal SC (2013). Anticoagulation in patients with traumatic brain injury. Curr Opin Anaesthesiol 26: 529-534.

Schochl H, Solomon C, Traintinger S et al. (2011). Thromboelastometric (ROTEM) findings in patients suffering from isolated severe traumatic brain injury. J Neurotrauma 28: 2033-2041.

Seel RT, Douglas J, Dennison AC et al. (2013). Specialized early treatment for persons with disorders of consciousness: program components and outcomes. Arch Phys Med Rehabil 94: 1908-1923.

ShaferA(1998). Complications of sedation with midazolam in the intensive care unit and a comparison with other sedative regimens. Crit Care Med 26: 947-956.

Sharshar T, Citerio G, Andrews PJ et al. (2014). Neurological examination of critically ill patients: a pragmatic approach. Report of an ESICM expert panel. Intensive Care Med 40: 484-495.

Shen X, Dutcher SK, Palmer J et al. (2015). A systematic review of the benefits and risks of anticoagulation following traumatic brain injury. J Head Trauma Rehabil 30: E29-E37.

Shively S, Scher AI, Perl DP et al. (2012). Dementia resulting from traumatic brain injury: what is the pathology? Arch Neurol 69: 1245-1251.

Shlosberg D, Benifla M, Kaufer D et al. (2010). Blood-brain barrier breakdown as a therapeutic target in traumatic brain injury. Nat Rev Neurol 6: 393-403.

Signorini DF, Andrews PJ, Jones PA et al. (1999). Adding insult to injury: the prognostic value of early secondary insults for survival after traumatic brain injury. J Neurol Neurosurg Psychiatry 66: 26-31.

Simard JM, Woo SK, Schwartzbauer GT et al. (2012). Sulfonylurea receptor 1 in central nervous system injury: a focused review. J Cereb Blood Flow Metab 32: 1699-1717.

Smith MJ, Stiefel MF, Magge S et al. (2005). Packed red blood cell transfusion increases local cerebral oxygenation. Crit Care Med 33: 1104-1108.

Smith DH, Johnson VE, Stewart W (2013). Chronic neuropathologies of single and repetitive TBI: substrates of dementia? Nat Rev Neurol 9: 211-221.

Sorrentino E, Budohoski KP, Kasprowicz M et al. (2011). Critical thresholds for transcranial Doppler indices of cerebral autoregulation in traumatic brain injury. Neurocrit Care 14: 188-193.

Sorrentino E, Diedler J, Kasprowicz M et al. (2012). Critical thresholds for cerebrovascular reactivity after traumatic brain injury. Neurocrit Care 16: 258-266.

Spahn DR, Bouillon B, Cerny V et al. (2013). Management of bleeding and coagulopathy following major trauma: an updated European guideline. Crit Care 17: R76.

Stein DM, Hu PF, Brenner M et al. (2011). Brief episodes of intracranial hypertension and cerebral hypoperfusion are associated with poor functional outcome after severe traumatic brain injury. J Trauma 71 : 364-373. discussion 373-364.

Stein DM, Lindell AL, Murdock KR et al. (2012). Use of serum biomarkers to predict cerebral hypoxia after severe traumatic brain injury. J Neurotrauma 29: 1140-1149. 
Steiner LA, Czosnyka M, Piechnik SK et al. (2002). Continuous monitoring of cerebrovascular pressure reactivity allows determination of optimal cerebral perfusion pressure in patients with traumatic brain injury. Crit Care Med 30: 733-738.

Steiner LA, Balestreri M, Johnston AJ et al. (2004). Sustained moderate reductions in arterial CO2 after brain trauma time-course of cerebral blood flow velocity and intracranial pressure. Intensive Care Med. 30 (12): $2180-2187$.

Steiner LA, Balestreri M, Johnston AJ et al. (2005). Predicting the response of intracranial pressure to moderate hyperventilation. Acta Neurochir (Wien). 147 (5): 477-483; discussion 483.

Stevens RD, Hannawi Y, Puybasset L (2014). MRI for coma emergence and recovery. Curr Opin Crit Care 20: 168-173.

Steyerberg EW, Mushkudiani N, Perel P et al. (2008). Predicting outcome after traumatic brain injury: development and international validation of prognostic scores based on admission characteristics. PLoS Med 5: e165. discussion e165.

Stocchetti N, Furlan A, Volta F (1996). Hypoxemia and arterial hypotension at the accident scene in head injury. J Trauma 40: 764-767.

Stocchetti N, Zanaboni C, Colombo A et al. (2008). Refractory intracranial hypertension and "second-tier" therapies in traumatic brain injury. Intensive Care Med 34: 461-467.

Stocchetti N, Paterno R, Citerio G et al. (2012). Traumatic brain injury in an aging population. J Neurotrauma 29: 1119-1125.

Strong AJ, Fabricius M, Boutelle MG et al. (2002). Spreading and synchronous depressions of cortical activity in acutely injured human brain. Stroke 33: 2738-2743.

Su SH, Wang F, Hai J et al. (2014). The effects of intracranial pressure monitoring in patients with traumatic brain injury. PLoS One 9: e87432.

Taher A, Pilehvari Z, Poorolajal J et al. (2016). Effects of Normobaric Hyperoxia in Traumatic Brain Injury: A Randomized Controlled Clinical Trial. Trauma Mon. 21 (1): e26772.

Takano T, Tian GF, Peng W et al. (2007). Cortical spreading depression causes and coincides with tissue hypoxia. Nat Neurosci 10: 754-762.

Teasdale G, Jennett B (1974). Assessment of coma and impaired consciousness.Apractical scale. Lancet 2: 81-84.

Teasdale GM, Nicoll JA, Murray G et al. (1997). Association of apolipoprotein E polymorphism with outcome after head injury. Lancet 350: 1069-1071.

Teasdale GM, Murray GD, Nicoll JA (2005). The association between APOE epsilon4, age and outcome after head injury: a prospective cohort study. Brain 128: 2556-2561.

Teasdale G, Maas A, Lecky F et al. (2014). The Glasgow Coma Scale at 40 years: standing the test of time. Lancet Neurol 13: 844-854.

Tepas JJ, Pracht EE, Orban BL et al. (2013). High-volume trauma centers have better outcomes treating traumatic brain injury. J Trauma Acute Care Surg 74: 143-147. discussion 147-148.

The Acute Respiratory Distress Syndrome Network (2000). Ventilation with lower tidal volumes as compared with traditional tidal volumes for acute lung injury and the acute respiratory distress syndrome. N Engl J Med 342: 1301-1308.

Timofeev I, Carpenter KL, Nortje J et al. (2011). Cerebral extracellular chemistry and outcome following traumatic brain injury: a microdialysis study of 223 patients. Brain 134: 484-494.

Turner-Stokes L (2014). Prolonged disorders of consciousness: new national clinical guidelines from the Royal College of Physicians, London. Clin Med (Lond) 14: 4-5.

Unden L, Calcagnile O, Unden J et al. (2015). Validation of the Scandinavian guidelines for initial management of minimal, mild and moderate traumatic brain injury in adults. BMC Med 13: 292.

Uzan M, Tanriverdi T, Baykara O et al. (2005). Association between interleukin-1 beta (IL-1beta) gene polymorphism and outcome after head injury: an early report. Acta Neurochir (Wien) 147: 715-720. discussion 720.

Vale FL, Burns J, Jackson AB et al. (1997). Combined medical and surgical treatment after acute spinal cord injury: results of a prospective pilot study to assess the merits of aggressive medical resuscitation and blood pressure management. J Neurosurg 87: 239-246.

Vallier HA, Wang X, Moore TA et al. (2013). Timing of orthopaedic surgery in multiple trauma patients: development of a protocol for early appropriate care. J Orthop Trauma 27: 543-551.

Van Beek JG, Mushkudiani NA, Steyerberg EW et al. (2007). Prognostic value of admission laboratory parameters in traumatic brain injury: results from the IMPACT study. J Neurotrauma 24: 315-328.

Van den Berghe G, Schoonheydt K, Becx P et al. (2005). Insulin therapy protects the central and peripheral nervous system of intensive care patients. Neurology 64: 1348-1353.

Vedantam A, Yamal JM, Rubin ML et al. (2016). Progressive hemorrhagic injury after severe traumatic brain injury: effect of hemoglobin transfusion thresholds. J Neurosurg 1-6. 
Veenith TV, Carter EL, Grossac J et al. (2014). Use of diffusion tensor imaging to assess the impact of normobaric hyperoxia within at-risk pericontusional tissue after traumatic brain injury. J Cereb Blood Flow Metab. 34 (10): 1622-1627.

Verweij BH, Muizelaar JP, Vinas FC et al. (2000). Impaired cerebral mitochondrial function after traumatic brain injury in humans. J Neurosurg 93: 815-820.

Vespa PM (2016). Brain hypoxia and ischemia after traumatic brain injury: is oxygen the right metabolic target? JAMA Neurol 73: 504-505.

Vespa PM, McArthur D, O'Phelan K et al. (2003). Persistently low extracellular glucose correlates with poor outcome 6 months after human traumatic brain injury despite a lack of increased lactate: a microdialysis study. J Cereb Blood Flow Metab 23: 865-877.

Vespa P, Bergsneider M, HattoriNet al. (2005). Metabolic crisis without brain ischemia is common after traumatic brain injury: a combined microdialysis and positron emission tomography study. J Cereb Blood Flow Metab 25: 763-774.

Vespa PM, McArthur DL, Xu Y et al. (2010). Nonconvulsive seizures after traumatic brain injury are associated with hippocampal atrophy. Neurology 75: 792-798.

Vik A, Nag T, Fredriksli OA et al. (2008). Relationship of "dose" of intracranial hypertension to outcome in severe traumatic brain injury. J Neurosurg 109: 678-684.

Vitek MP, Brown CM, Colton CA (2009). APOE genotypespecific differences in the innate immune response. Neurobiol Aging 30: 1350-1360.

von Steinbuchel N, Wilson L, Gibbons H et al. (2010). Quality of Life after Brain Injury (QOLIBRI): scale validity and correlates of quality of life. J Neurotrauma 27: 1157-1165.

Vos PE, Lamers KJ, Hendriks JC et al. (2004). Glial and neuronal proteins in serum predict outcome after severe traumatic brain injury. Neurology 62: 1303-1310.

Wafaisade A, Lefering R, Tjardes T et al. (2010a). Acute coagulopathy in isolated blunt traumatic brain injury. Neurocrit Care 12: 211-219.

Wafaisade A, Wutzler S, Lefering R et al. (2010b). Drivers of acute coagulopathy after severe trauma: a multivariate analysis of 1987 patients. Emerg Med J 27: 934-939.

Wang HK, Lu K, Liliang PC et al. (2012). The impact of tracheostomy timing in patients with severe head injury: an observational cohort study. Injury 43: 1432-1436.

Warner MA, O'Keeffe T, Bhavsar P et al. (2010). Transfusions and long-term functional outcomes in traumatic brain injury. J Neurosurg 113: 539-546.

Washington PM, Villapol S, Burns MP (2016). Polypathology and dementia after brain trauma: does brain injury trigger distinct neurodegenerative diseases, or should they be classified together as traumatic encephalopathy? Exp Neurol 275 (Pt 3): 381-388.

Waters RJ, Murray GD, Teasdale GM et al. (2013). Cytokine gene polymorphisms and outcome after traumatic brain injury. J Neurotrauma 30: 1710-1716.

WHO (2006). Neurological disorders: public health challenges, Switzerland, World Health Organization, Geneva.

Wijdicks EF, Bamlet WR, Maramattom BV et al. (2005). Validation of a new coma scale: the FOUR score. Ann Neurol 58: 585-593.

Willmott C, Ponsford J, McAllister TW et al. (2013). Effect of COMT Val158Met genotype on attention and response to methylphenidate following traumatic brain injury. Brain Inj 27: 1281-1286.

Winkler EA, Yue JK, McAllisterTWet al. (2016). COMT Val158 Met polymorphism is associated with nonverbal cognition following mild traumatic brain injury. Neurogenetics 17: 31-41.

Wunsch H, Angus DC, Harrison DA et al. (2011). Comparison of medical admissions to intensive care units in the United States and United Kingdom. Am J Respir Crit Care Med 183: 1666-1673.

Xu JC, Shen J, Shao WZ et al. (2016). The safety and efficacy of levetiracetam versus phenytoin for seizure prophylaxis after traumatic brain injury: a systematic review and meta-analysis. Brain Inj 1-8.

Yamal JM, Rubin ML, Benoit JS et al. (2015). Effect of hemoglobin transfusion threshold on cerebral hemodynamics and oxygenation. J Neurotrauma 32: 1239-1245.

Yanamadala V, Walcott BP, Fecci PE et al. (2014). Reversal of warfarin associated coagulopathy with 4factor prothrombin complex concentrate in traumatic brain injury and intracranial hemorrhage. J Clin Neurosci 21: $1881-1884$.

Yuan Q,WuX, SunYet al. (2015). Impact of intracranial pressure monitoring on mortality in patients with traumatic brain injury: a systematic review and meta-analysis. J Neurosurg 122: 574-587.

Yue JK, Pronger AM, Ferguson AR et al. (2015). Association of a common genetic variant within ANKK1 with six month cognitive performance after traumatic brain injury. Neurogenetics 16: 169-180.

Zygun DA, Nortje J, Hutchinson PJ et al. (2009). The effect of red blood cell transfusion on cerebral oxygenation and metabolism after severe traumatic brain injury. Crit Care Med 37: 1074-1078. 